\title{
Molecular profiling for precision cancer therapies
}

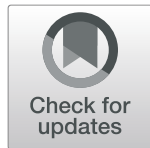

Eoghan R. Malone ${ }^{1 \dagger}$, Marc Oliva ${ }^{1 \dagger}$, Peter J. B. Sabatini ${ }^{2}$, Tracy L. Stockley ${ }^{2}$ and Lillian L. Siu ${ }^{{ }^{*}}$

\begin{abstract}
The number of druggable tumor-specific molecular aberrations has grown substantially in the past decade, with a significant survival benefit obtained from biomarker matching therapies in several cancer types. Molecular pathology has therefore become fundamental not only to inform on tumor diagnosis and prognosis but also to drive therapeutic decisions in daily practice. The introduction of next-generation sequencing technologies and the rising number of large-scale tumor molecular profiling programs across institutions worldwide have revolutionized the field of precision oncology. As comprehensive genomic analyses become increasingly available in both clinical and research settings, healthcare professionals are faced with the complex tasks of result interpretation and translation. This review summarizes the current and upcoming approaches to implement precision cancer medicine, highlighting the challenges and potential solutions to facilitate the interpretation and to maximize the clinical utility of molecular profiling results. We describe novel molecular characterization strategies beyond tumor DNA sequencing, such as transcriptomics, immunophenotyping, epigenetic profiling, and single-cell analyses. We also review current and potential applications of liquid biopsies to evaluate blood-based biomarkers, such as circulating tumor cells and circulating nucleic acids. Last, lessons learned from the existing limitations of genotype-derived therapies provide insights into ways to expand precision medicine beyond genomics.
\end{abstract}

\section{Background}

In the past decade, the field of oncology has witnessed substantial changes in the way patients with cancer are managed, with departure from a "one-size-fits-all" approach and increasing focus on precision medicine based on genomic variants. Cancer precision medicine is defined as "the use of therapeutics that are expected to confer benefit to a subset of patients whose cancer displays specific molecular or cellular features (most commonly genomic changes and changes in gene or protein expression patterns)" [1]. In certain tumors, molecular profiling may also yield clinically relevant diagnostic and prognostic information. Owing to the genomic complexity of cancers, precision medicine has been enabled by a growing body of knowledge that identifies key drivers of oncogenesis, coupled with advances in tumor analysis by next-generation sequencing (NGS) and other profiling technologies, and by the availability of new

\footnotetext{
* Correspondence: lillian.siu@uhn.ca

${ }^{\dagger}$ Eoghan Malone and Marc Oliva contributed equally to this work.

'Division of Medical Oncology and Hematology, Princess Margaret Cancer Centre, University Health Network, Department of Medicine, University

Avenue, University of Toronto, Toronto, Ontario M5G 125, Canada

Full list of author information is available at the end of the article
}

therapeutic agents. Precision medicine has already transformed cancer care: both common and rare malignancies can be targeted by specific therapies to improve clinical outcomes in patients (Table 1). This review focuses on current and emerging approaches, highlights successes and challenges, and proposes potential solutions in the implementation of precision medicine in clinical research and practice (Fig. 1). The expansion to other molecular characterization technologies beyond genomics, such as transcriptomics, epigenetics, and immunophenotyping, and to the evaluation of drug combinations beyond monotherapy approaches will hopefully increase the clinical utility and scope of precision medicine. Last, patients represent active key stakeholders in precision medicine initiatives; thus, resources must be deployed to optimize their education and engagement.

\section{Current and emerging molecular approaches to enable precision medicine Integration of precision medicine with other diagnostic tests in clinical practice}

First and foremost, the important interactions between research and standard of care testing in precision cancer 
Table 1 FDA and EMA approved biomarker matching targeted drugs and routine molecular pathology testing [2,3]

\begin{tabular}{|c|c|c|c|c|}
\hline Gene/protein & Anticancer agent & Indications & Biomarker & Routine testing \\
\hline ALK & $\begin{array}{l}\text { Crizotinib, ceritinib, } \\
\text { alectinib, lorlatinib, } \\
\text { brigatinib }\end{array}$ & NSCLC & ALK translocation & $\mathrm{FISH}, \mathrm{IHC}$ \\
\hline $\begin{array}{l}\text { Androgen receptor } \\
\text { (AR) }\end{array}$ & $\begin{array}{l}\text { Abiraterone, enzalutamide, } \\
\text { dalurotamide, apalutamide }\end{array}$ & Prostate cancer & AR expression & $\mathrm{HC}$ \\
\hline$B C L-2$ & Venetoclax & Chronic myeloid leukemia & $\begin{array}{l}\text { BCL-2 protein expression, } \\
B C L-2 \text { amplification/ } \\
\text { translocation }\end{array}$ & $\mathrm{IHC}, \mathrm{FISH}$ \\
\hline$B C R / A B L$ & $\begin{array}{l}\text { Imatinib, dasatinib, nilotinib, } \\
\text { bosutinib, ponatinib }\end{array}$ & Chronic myeloid leukemia & $B C R / A B L 1$ fusion & $\begin{array}{l}\text { IHC (FISH, DNA/ } \\
\text { RNA sequencing), } \\
\text { PCR }^{1}\end{array}$ \\
\hline BRAF & $\begin{array}{l}\text { Dabrafenib+trametinib, } \\
\text { vemurafenib+cobimetinib, } \\
\text { encorafenib+binimetinib }\end{array}$ & $\begin{array}{l}\text { Melanoma, NSCLC, anaplastic } \\
\text { thyroid cancer, hairy cell } \\
\text { leukemia }\end{array}$ & BRAF V600E/K mutations & $\begin{array}{l}\mathrm{IHC}^{\mathrm{H}}, \mathrm{PCR}^{1}, \mathrm{DNA} \\
\text { sequencing }\end{array}$ \\
\hline$B R C A$ & Olaparib, talazoparib, rucaparib & Breast cancer, ovarian cancer & $\begin{array}{l}\text { Germline/somatic BRCA } 1 / 2 \\
\text { mutations }\end{array}$ & DNA sequencing \\
\hline C-KIT, PDGFR & Imatinib & Gastrointestinal stromal tumor & $\begin{array}{l}\text { C-KIT Exon } 9 \text { and } 11 \\
\text { mutations, PDGFR mutations }\end{array}$ & $\begin{array}{l}\text { IHC, DNA } \\
\text { sequencing }\end{array}$ \\
\hline PDGFRB & Imatinib & $\begin{array}{l}\text { Myelodysplastic/ } \\
\text { myeloproliferative syndromes }\end{array}$ & PDGFRB rearrangement & $\mathrm{FISH}$ \\
\hline $\begin{array}{l}\text { Estrogen/ } \\
\text { progesterone } \\
\text { receptors (ER/PR) }\end{array}$ & $\begin{array}{l}\text { Tamoxifen, raloxifene, fulvestrant, } \\
\text { toremifine }\end{array}$ & Breast cancer & ER/PR expression & $\mathrm{HC}$ \\
\hline erBB2/HER-2 & $\begin{array}{l}\text { Trastuzumab, pertuzumab, } \\
\text { ado-trastuzumab, emtansine, } \\
\text { neratinib }\end{array}$ & Breast cancer, gastric cancer & $\begin{array}{l}\text { HER-2 protein expression, } \\
\text { HER-2 amplification }\end{array}$ & IHC, FISH \\
\hline \multirow[t]{2}{*}{ EGFR } & $\begin{array}{l}\text { Gefitinib, erlotinib, afatinib, } \\
\text { dacomitinib }\end{array}$ & NSCLC & $\begin{array}{l}\text { EGFR exon } 19 \text { deletion, exon } \\
21 \text { L858R mutation }\end{array}$ & $\begin{array}{l}\text { DNA sequencing, } \\
\text { PCR }^{1}\end{array}$ \\
\hline & Osimertinib & & EGFR T790M mutation & \\
\hline FGFR2/3 & Erdafitinib & Bladder cancer & $\begin{array}{l}\text { FGFR3 mutations, FGFR2/3 } \\
\text { fusions }\end{array}$ & $\begin{array}{l}\text { DNA sequencing, } \\
\text { FISH }\end{array}$ \\
\hline FLT3 & Midostaurin, gilteritinib & Acute myeloid leukemia & FLT3 mutations & $\begin{array}{l}\text { DNA sequencing, } \\
P^{\prime} R^{1}\end{array}$ \\
\hline IDH1/2 & Ivosidenib, enasidenib & Acute myeloid leukemia & IDH1/2 mutations & $\begin{array}{l}\text { IHC, DNA } \\
\text { sequencing }\end{array}$ \\
\hline MET & $\begin{array}{l}\text { Crizotinib (breakthrough } \\
\text { designation) }\end{array}$ & NSCLC & $\begin{array}{l}\text { MET amplification, MET exon } \\
14 \text { alterations }\end{array}$ & $\begin{array}{l}\text { FISH, DNA/RNA } \\
\text { sequencing }\end{array}$ \\
\hline \multirow[t]{2}{*}{ MSI-H or dMMR } & Pembrolizumab & MSI-H or dMMR solid tumors & \multirow{2}{*}{$\begin{array}{l}\text { MLH1, MSH2, MSH6, PMS2 } \\
\text { protein expression, MSI high }\end{array}$} & \multirow{2}{*}{$\begin{array}{l}\text { IHC, DNA } \\
\text { sequencing, } P C R^{1}\end{array}$} \\
\hline & Nivolumab and ipilimumab & Colorectal cancer & & \\
\hline NTRK & Larotrectinib, entrectinib & Solid tumors with NTRK fusions & $\begin{array}{l}\text { NTRK protein expression, } \\
\text { NTRK fusion }\end{array}$ & $\begin{array}{l}\text { IHC, FISH, DNA/RNA } \\
\text { sequencing }\end{array}$ \\
\hline PISKCA & Alpelisib & Breast cancer & PI3KCA mutation & DNA sequencing \\
\hline $\begin{array}{l}\text { PI3K (alpha and } \\
\text { delta) }\end{array}$ & Copanlisib & Follicular lymphoma & PI3K mutation & DNA sequencing \\
\hline $\begin{array}{l}\text { PI3K (delta and } \\
\text { gamma) }\end{array}$ & Duvelisib & $\begin{array}{l}\text { Chronic lymphocytic leukemia, } \\
\text { small lymphocytic lymphoma }\end{array}$ & PI3K mutation & DNA sequencing \\
\hline $\begin{array}{l}\text { RAS (negative } \\
\text { predictor) }\end{array}$ & Cetuximab, panitumumab & Colorectal cancer & KRAS/NRAS wildtype & DNA sequencing \\
\hline RET & $\begin{array}{l}\text { LOXO-292 (breakthrough } \\
\text { designation) }\end{array}$ & NSCLC, medullary thyroid cancer & RET fusion, RET mutation & $\begin{array}{l}\text { FISH, DNA/RNA } \\
\text { sequencing }\end{array}$ \\
\hline ROS1 & Crizotinib, entrectinib & NSCLC & ROS translocation & $\begin{array}{l}\text { FISH, DNA/RNA } \\
\text { sequencing }\end{array}$ \\
\hline
\end{tabular}




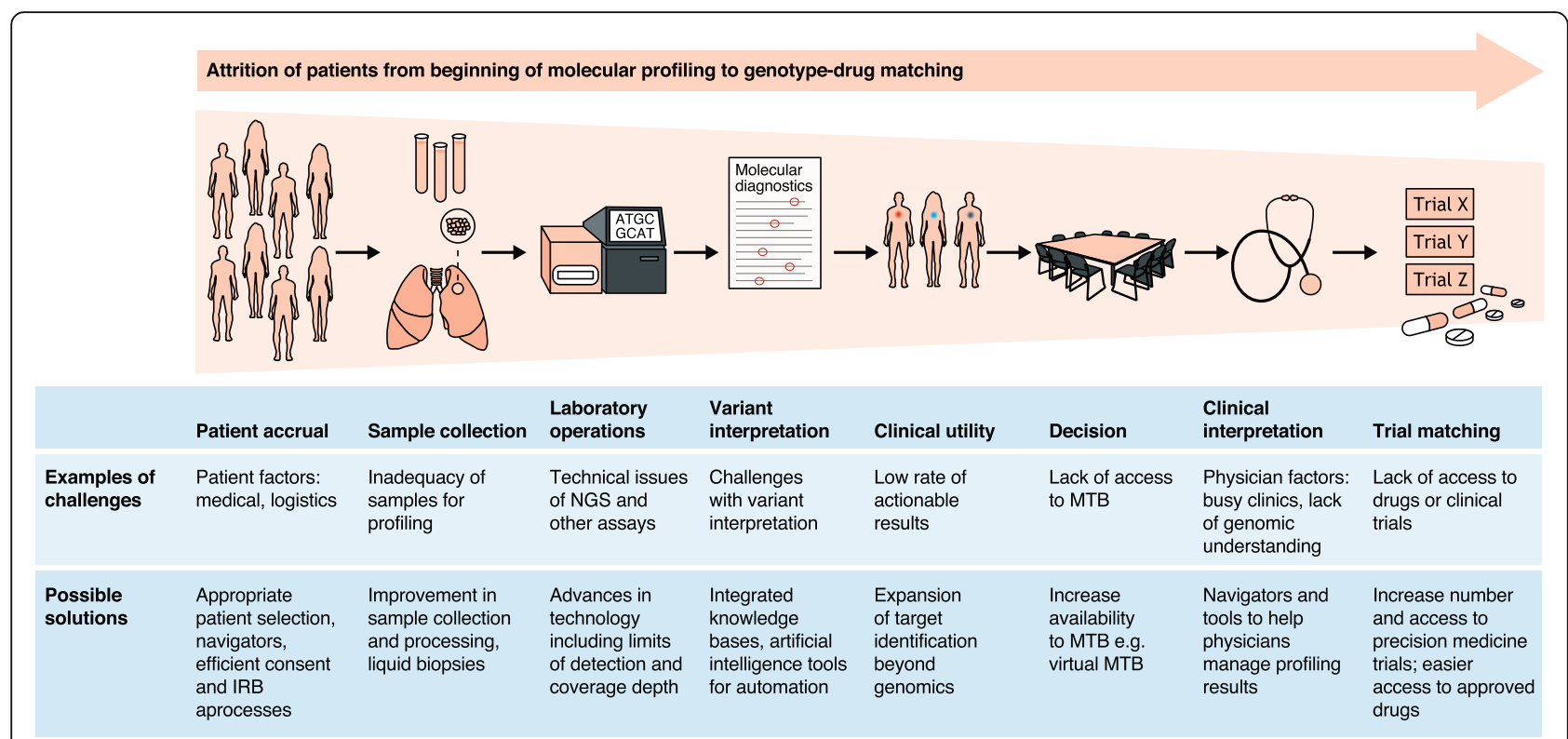

Fig. 1 The process from genetic sequencing of patients to enrollment on genotype-matched clinical trials. MTB, molecular tumor board; IRB, institutional review board; NGS, next-generation sequencing

medicine must be highlighted. Large-scale research studies may identify new biomarkers with clinical utility, which can then be taken up as a new standard of care clinical diagnostic test to maximize the benefit to the patient population. Many tumor-specific molecular alterations, including protein overexpression, mutations in driver genes, or rearrangements, are well-proven predictive biomarkers of response to selective targeted therapies, with additional biomarkers rapidly emerging. Clinical molecular pathology analysis has therefore become an indispensable laboratory tool that can be used to characterize tumor biology and to drive therapeutic decisions.

Conventional tests such as immunohistochemistry (IHC) and fluorescence in situ hybridization (FISH) are fundamental precision medicine tools in daily practice [4], with many biomarkers currently detected by these two techniques (Table 1). IHC can detect changes at the protein level that result not only from gene aberrations, most commonly gene amplifications, but also from specific DNA rearrangements or point mutations (such as EML4-ALK translocation in non-small cell lung cancer (NSCLC) and IDH1/2 mutations in glioma) [5-7]. The use of IHC has extended to biomarkers of response to immuno-oncology (IO) agents, including PD-L1 expression or mismatch repair status, which determine the eligibility for therapies that are based on anti-PD-1/PD-L1 agents in certain tumor types [1, 4, 5, 8-10]. FISH has been the gold-standard technique for determining DNA rearrangements, and it is also routinely used to confirm amplifications at the gene level when IHC results are equivocal $[11,12]$.
As the number of druggable gene aberrations and predictive biomarkers grow in oncology, NGS technologies have increasingly substituted for conventional techniques, such as single-gene testing, and for targeted mutational platforms in routine molecular pathology. Conventional techniques have high sensitivity and specificity in detecting actionable mutations with proven benefit from matched targeted therapies or in identifying mutations that are associated with resistance to specific drugs [13-16]. However, with these techniques, each biomarker must be prespecified in order to be detected and a purpose-made assay is required for each analyte. NGS can enable the simultaneous analysis of a broad spectrum of genomic alterations, including mutations, copy number variations (CNV), translocations, and fusions in multiple genes. It therefore provides a more efficient, cost- and tissue-saving tumor analysis as compared to serial single-biomarker analyses $[17,18]$, particularly in the context of the genomic complexity that is known to exist within tumors. Several studies comparing NGS performance against reverse transcriptase (RT)-PCR-based targeted mutation platforms, single-gene testing and other conventional techniques have shown similar sensitivity and specificity in detecting common druggable genomic aberrations in daily practice [19-21]. Given the decreasing costs and turnaround time of NGS, the improvement in bioinformatics analyses, and the harmonization of knowledgebases to facilitate the clinical interpretation of genomic results, the move to comprehensive genomic profiling by NGS in clinical testing is compelling in the precision cancer medicine context. 
Current applications of NGS approaches: targeted gene panels vs whole exome and whole genome sequencing NGS can be limited to a pre-specified group of genes (targeted gene panels), can focus on the coding regions of all of the base pairs of the genome (whole exome sequencing (WES)), or can involve the analysis of the entire tumor genome, including the intronic regions (whole genome sequencing (WGS)). The choice between these approaches depends on several factors, including the final application of tumor testing (clinical vs research), the results required, technical efficiency, and cost (Additional file 1) [17]. To date, WES and WGS have been largely confined to the research space, with the goal of collecting large amounts of genomic information for translational research applications that can improve knowledge in cancer biology over time. Targeted gene panels have been used preferably in the clinical setting because they provide greater depth of coverage in selected areas of interest (e.g., hotspot regions with known actionable mutations), faster turnaround, and more clinically relevant data when compared to broader genomic profiling by WES or WGS approaches [22]. The number of genes included in these panels can vary, ranging from 20-30 to over 400-500 genes. Although the clinical utility of assessing all of the genes that are included in large panels is currently uncertain, the benefit of simultaneous multi-gene testing using NGS and the low incremental cost of including additional genes are motivators for using more comprehensive genomic profiling in the clinic.

A significant challenge is that although large-scale tumor sequencing studies and genotype-matched trials have reported actionable mutations in driver genes in up to $40 \%$ of the patients, a significantly lower proportion of patients (10-15\%) end up being treated with genotypematched drugs [23-28]. Multiple factors are at play, but the key challenge is the lack of approved or investigational agents to match specific driver alterations. In cases where the target molecular aberration occurs infrequently, the recruitment of patients who have such rare mutations into clinical trials can be challenging and can hinder the development of new drugs. Furthermore, intratumoral heterogeneity (e.g., trunk vs branch mutations) and whether or not a specific molecular alteration is a "true" driver in a particular tumor can ultimately impact the efficacy of the matched therapy [29]. In this regard, Hess et al. [30] have recently revealed that many somatic hotspot mutations that are thought to be involved in tumorigenesis and labeled as "drivers" might actually be recurrent passenger mutations, which occur in areas of the genome that are highly mutable.

A recent retrospective analysis in NSCLC showed no survival gain in patients who underwent genomic profiling using multi-gene targeted panels compared to patients who underwent only single-gene testing of EGFR and $A L K$ genes, with panel testing offering additional opportunities for targeted therapy to fewer than $5 \%$ of patients [31]. However, broader genomic analyses, looking beyond actionable variants in known genes, have the potential to inform on acquired resistance to treatments (for example, the EGFR T790M mutation confers resistance to first-generation EGFR tyrosine kinase inhibitors (TKI) in NSCLC) or to suggest potential synergistic drug combinations (for example, downstream activation of the BRAF pathway led to the combination of BRAF and MEK inhibitors in BRAF mutant melanoma) [32, 33]. The abovementioned findings resulted in the incorporation of new treatment options in patients with EGFR-mutant NSCLC (such as osimertinib) [34, 35] and $B R A F$-mutant NSCLC $[36,37]$ and melanoma (such as the dabrafenib and trametinib combination) [38], which have led to a significant improvement in survival in these patient populations and ultimately changed the standard of care.

Advances in sequencing technologies such as WGS have facilitated the simultaneous detection of single nucleotide variants (SNV), CNV, and structural rearrangements such as gene fusions, leading to greater diagnostic yield of actionable findings in tumor samples. The value of performing comprehensive genomic profiling is exhibited by a recent study that characterized 2520 samples of metastatic tumors with paired normal tissue. WGS was used to identify the catalog of genetic mutations found in each metastasis, thus illuminating the genomic changes present in the metastases of 22 solid tumors, and 62\% were found to contain at least 1 actionable event [39]. Similar evaluations were also performed on pediatric pan-cancer cohorts to identify driver genes [40]. New sequencing approaches have extended the length of sequencing fragments to more than a few kilobases, thus improving the ability to detect complex structural alterations in the genome [41]. One study using genomic DNA from patients who had a variety of brain cancers was able to detect SNV, CNV, and methylation profiles simultaneously from a low-pass WGS approach using long-read sequencing [42]. In cancer, most long-read sequencing efforts have focused on RNA sequencing and have discovered novel fusion and splicing isoforms that are relevant to tumor progression or treatment resistance [43-46]. Currently, the error rates for long-read technologies are too high for somatic variant detection, but the movement towards these approaches for tumor analysis would provide a holistic approach to genomic tumor profiling and would improve personalized therapeutic management.

\section{Circulating biomarkers}

The quality, quantity, and availability of tumor tissue from cancer patients pose challenges to the clinical implementation of precision medicine. The processing of formalin-fixed, paraffin-embedded fragments can alter nucleic acids, and low tumor content in tumor samples 
can decrease test sensitivity or lead to false-positive mutation calls [17]. In addition, the use of archival tissue or biopsies collected at a single time point may not account for intratumoral heterogeneity in space or time [47-49]. Acquisition of multiple tumor biopsies to overcome this is hindered by the need for invasive procedures that not only put patient safety at risk but also require a significant amount of resources.

An emerging field that may ameliorate some tumor sample issues is the testing of circulating tumor-specific markers. These include circulating tumor cells (CTC) or circulating tumor DNA (ctDNA), as well as RNAs, proteins, or metabolites, that are present in body fluids such as the blood, urine, and peritoneal or cerebrospinal fluid [50-54]. Liquid biopsies are easily accessible through minimally invasive procedures that can be repeated to provide a dynamic and longitudinal assessment of tumor-specific diagnostic, prognostic, or predictive biomarkers. NGS can be applied to plasma CTC and ctDNA, providing a more comprehensive picture of the tumor genomic landscape than can be obtained from tumor tissue, as it reflects different tumor regions (such as primary and metastatic sites) and thus tackles intratumoral heterogeneity $[55,56]$. Single-cell analysis of CTC also allows multi-omic assessment and enables the generation of patient-specific tumor models, such as organoids and xenografts. Viable CTC are thought to be involved in the formation of tumor metastasis and thus may reflect a metastatic genotype. Therefore, single-cell analyses can lead to the detection of actionable aberrations that are implicated in metastatic spread [57], whereas tumor models derived from CTC might serve to test novel drugs or sensitivity to current standard therapies $[58,59]$.

Potential clinical uses of blood-based CTC and ctDNA that are not offered by tumor tissue sequencing include monitoring the persistence of radiologically undetectable tumors (e.g., minimal or molecular residual disease), prediction of recurrence (e.g., persistent CTC associated with risk of relapse in breast cancer) [60], monitoring of treatment response (e.g., CTC dynamics in prostate and breast cancer patients treated with chemotherapy) [61, 62], early detection of resistance mechanisms [63, 64], assessment of tumor burden (e.g., correlation between tumor burden and ctDNA variant allele frequency in NSCLC) [65], tracking the clonal evolution of tumors [66], and dynamic evaluation of immune biomarkers such as PD-L1 expression and tumor mutation burden [67-69].

To date, two tests based on plasma ctDNA analysis have been FDA-approved for clinical use: the testing of EGFR mutations in patients with NSCLC and the methylation of the SEPT9 promoter as screening for colorectal cancer $[56,64,67,70]$. Topics that remain to be addressed include the high variability of CTC and plasma ctDNA levels between individual patients that result from inconsistent shedding and the impact of disease burden and/or cancer type on circulating nucleic acids [47].

Beyond CTC and ctDNA, other circulating tumor biomarkers such as RNA, proteins, and metabolites are still in early phases of development and need to be explored properly. At present, there are no FDA-approved assays for the detection and analysis of these biomarkers and their clinical utility remains unclear [50]. Circulating-free microRNAs (miRNA) are of particular interest because of their stability and high abundance in the plasma, and miRNA signatures are being investigated as diagnostic and prognostic biomarkers in several tumor types, including for the detection of minimal residual disease [71-73]. However, the variability and lack of reproducibility of the results across studies, which result from the lack of standardized methods for collection and analyses, remain the main challenges [74, 75]. There is an urgent need for methodological standardization to exploit the full potential of liquid biopsies in the clinic, and multiple initiatives to address this need are ongoing [75].

\section{Taking actions on genomic results Identification and clinical interpretation of genomic results}

The interpretation of the clinical impact of tumor variants in the context of a specific cancer and for individual patients is an active field of study in precision cancer medicine [63]. To facilitate variant annotation and clinical interpretation, genomic databases and online resources have compiled associations with a specific histology or disease, as well as their prognostic and/or predictive value of response to specific therapies [76]. The data collected in these knowledgebases vary depending on their final scope, ranging from pre-clinical biological and functional data for translational research applications (e.g., The Cancer Genome Atlas (TCGA), International Cancer Genome Consortium (ICGC)) to the most updated evidence on the clinical benefit obtained from matched drugs that can be used to drive variant-specific treatment recommendations (e.g., OncoKB, MyCancerGenome, CIViC) [77, 78]. Other sources are specifically focused on passenger variant curation (e.g., dbCPM) [79]. Datasets such as MyCancerGenome or CIViC also help to discriminate driver variants (which are implicated in tumor growth and proliferation) from passenger tumor variants (incidental variants that do not confer survival or clonal advantage). Of note, these datasets might need to be revised in the light of the recent findings from Hess et al. [30] (see the "Current applica tions of NGS approaches: targeted gene panels vs whole exome and whole genome sequencing" section). Current statistical models that are used to account for background tumor mutability at the gene level, in an attempt to discriminate between driver and passenger mutations, are inaccurate and might lead to high rates of false positives, 
i.e., identification of driver variants that are actually passengers. The new model proposed by Hess et al. [30] accounts for mutability at the level of individual base pairs and, as such, has increased power and specificity to distinguish true driver mutations. In those cases where annotated variants are unknown or have not been previously reported, a few available website-based approaches can provide information on the predicted biological effects of novel variants on the basis of in silico tools and metaprediction methods (e.g., dbNSFP) [80, 81]. Germline-based genomic databases (e.g., National Center for Biotechnology Information (NCBI) ClinVar, Online Mendelian Inheritance in Man (OMIM)) that compile previously reported germline polymorphisms may also aid in differentiating tumor-specific somatic variants from non-pathogenic DNA variations in patients for whom no available matched normal tissue or blood is available [82, 83].

One of the major downsides of having multiple knowledgebases is the dispersion of the genomic information. New user-friendly tools have been developed to integrate the knowledge from established databases on diseases, genes, variants, and drugs (from basic biology to clinical evidence) in a single space, with the ultimate goal of improving clinical interpretation by healthcare professionals [84]. In addition, the existence of independent resources with different curators and scopes can lead to inconsistent or incomplete data collection on variants across platforms and to different format presentation and nomenclature, which can generate knowledge gaps and thus hamper the interpretation of variant actionability. Continued efforts to standardize variant curation and cataloging are needed to guarantee the utility of the genomic data provided. In this regard, a consensus set of minimal variant level data (MVLD) for tumor variant curation with a focus on clinical utility has been proposed by the Somatic Working Group of the Clinical Genome [84]. The generated data framework goes beyond genomic descriptive information to include data on clinical impact, such as biomarker class (diagnostic, prognostic, predictive), matched drugs available, and therapeutic effect (responsive vs resistant). Other global harmonization initiatives for variant curation and interpretation, such as the Global Alliance for Genomics Health (GA4GH) Variant Interpretation for Cancer Consortium (VICC), have also been proposed [85].

The implementation of guidelines and consensus to standardize somatic variant annotation, classification, and reporting is critical to enable the interpretation of variants across institutions and professionals. The Association for Molecular Pathology, American Society of Clinical Oncology, and College of American Pathologists have published a series of recommendations for the classification and reporting of somatic variants in cancer patients, which are based on their clinical significance and the available supporting evidence [86]. Evidencebased variant categorization aims to help clinicians in translating the potential actionability of somatic variants into clinical decision-making.

The detection of clinically relevant germline mutations in patients undergoing tumor genomic profiling has been reported [86, 87]. This is especially important for cancers with a large inherited component, such as breast, ovarian, and colorectal cancers. For example, the molecular assessment of colorectal cancer to identify sporadic vs inherited Lynch syndrome has traditionally involved a multi-step approach, which uses sequential testing mismatch repair proteins by IHC, microsatellite instability, and then additional molecular testing for somatic changes to rule out sporadic cases. Upfront tumor profiling with an NGS panel that includes sequencing for mismatch repair proteins, sequencing for other recurrent somatic changes (e.g., $B R A F$ ), and assessment of microsatellite instability proved to have greater sensitivity than IHC in identifying Lynch syndrome in patients with colorectal cancer [88]. For ovarian cancer, somatic tumor profiling of $B R C A 1$ and $B R C A 2$ for PARP inhibitor therapy may reveal inherited germline mutations in these genes. To address these issues, recent guidance from the European Society of Medical Oncology Precision Medicine Working Group recommends that germline-focused analysis should be performed during tumor-only genomic profiling to identify variants with high allele frequencies $(>20-30 \%)$ and selected genes of clinical relevance [87]. Referral to genetic subspecialties is also recommended for familial management and long-term follow-up.

\section{Molecular tumor board}

Large-scale genomic sequencing is currently available through academic institutions and private enterprises and is now funded in some jurisdictions but not in others; for instance, funding is now provided by Medicare in the USA. Target-drug matching can become increasingly complex as more information becomes available through the use of large panel tests or WES/ WGS approaches. There are expanding numbers of patients with complex genomic data that are in need of interpretation. In order to exploit the potential of NGSdriven therapy fully, a formal entity such as a molecular tumor board (MTB) should exist that brings interdisciplinary expertise into the evaluation of patients who have advanced cancer to indicate when alteration-driven treatment is advisable. These multi-disciplinary teams typically include oncologists, research scientists, bioinformaticians, pathologists, medical geneticists, genetic counselors, and genomicists, among others. They examine each patient's clinical, pathologic, and molecular information, review the literature and available resources, 
carry out discussions to reach a consensus if possible, and make treatment suggestions [89]. Previous studies have shown that interdisciplinary tumor boards can result in significant changes in treatment decisions [90-93]. The impact of MTB on outcomes has not yet been studied indepth, but they can help to identify patients for clinical trials, educate participants, facilitate collaboration, and ensure that providers across multiple locations are testing and treating patients in a uniform and consistent manner, based on clinical practice guidelines and best available evidence.

Published studies have identified a knowledge gap and lack of confidence of physicians in their ability to interpret sequencing data. For instance, $22 \%$ of physicians at a tertiary cancer center reported a lack of confidence in their genomic knowledge, so there is clearly a need to educate oncologists in interpreting genomics data [94]. Younger oncologists have been found to be more likely to use NGS testing than older colleagues. Physicians who have access to an MTB have also been found to increase their use of NGS [95]. MTB can improve clinicians' understanding of assay strengths, limitations, and results; can increase oncologists' confidence in the application of molecular diagnostics; and ultimately can enhance the success of precision medicine.

There are various challenges to implementing a successful MTB; for instance, it is not always possible for members to meet in person, the MTB may not always be accessible by community oncologists, and there is a lack of standard quality requirements and guidelines on how to run an MTB and make treatment decisions [90]. A solution to some of these issues is the use of virtual MTB. Interactive virtual MTB allows participation by a variety of healthcare professionals across a wide geographic area. In addition, virtual MTB can involve both a major academic center and a community cancer program to facilitate information exchange and maximize clinical trial accrual. The development of guidelines can be achieved by deriving broad-based consensus from experts in MTB panels and those in professional associations.

\section{Applicability of genomic results outside of approved indications}

The application of NGS may provide the treating physician with a list of druggable alterations. However, approved drugs are often inaccessible to biomarker-positive patients who have different tumor types because of a lack of reimbursement for drugs that are being used beyond their labeled indications. As a result, patients either need to be treated within the auspice of clinical trials or enrolled in compassionate access programs. Most clinical trials only cover a minority of potential genomic treatment indications and often have strict inclusion and exclusion criteria. Some molecular screening programs have performed gene panels to identify patients for opportunistic enrollment into early phase trials of targeted agents, whereas others have channeled patients to prospective biomarker-driven studies that sought out specific aberrations [24, 25, 96-98].

Large-scale tumor profiling studies using NGS have revealed significant genomic similarities, with shared actionable alterations in driver genes, among different tumor types (e.g., $B R A F$ mutations are found across multiple tumor types) $[99,100]$. As a result, the paradigm of precision oncology has shifted to "pan-cancer" biomarker-based approaches for therapeutic selection. The predictive value of NTRK fusions as biomarkers of response to TRK kinase inhibitors (larotrectinib, entrectinib) is a successful illustration of this approach. Both drugs have now been approved by the FDA to treat all solid tumors carrying NTRK fusions, and thus, TRK kinase inhibitors represent the second approved group of tissueagnostic drugs in cancer, following pembrolizumab for patients with MSI-high tumors [101]. Nevertheless, the implementation of pan-cancer biomarker testing in routine practice is challenging. The incidence of actionable genome aberrations is low overall and highly variable across tumor types, necessitating the testing of large numbers of tumors with significant use of resources. In the specific case of NTRK fusions, a diagnostic algorithm based on the incidence by tumor type and NTRK expression by IHC testing has been proposed as a more efficient detection strategy in routine practice [102-105].

\section{Ways to expand precision medicine Mutational signatures}

As discussed, genomic profiling for cancer precision medicine has a significant focus on finding discreet driver mutations that are associated with therapeutic targets or that are of diagnostic or prognostic value. An additional genomic tool in cancer are genomic "profiles" that harbor similar patterns of gene expression or of inherited or somatic mutations across multiple genes or genomic regions. With proper analysis, it is possible to group patients into subcategories for response, outcomes, or other clinical features. Mutational signatures expand genomics beyond the simple focus of discreet variant detection, with risk profiles reported in numerous cancer types including hepatocellular carcinoma, breast cancer, brain cancer, and diffuse large B cell lymphoma [106-108]. These approaches offer the potential for increased diagnostic yield, as a conventional single gene or panel testing cannot account for the complete array of mutational impacts. However, one study found that germline mutations in $B R C A 1$ and $B R C A 2$ responded to carboplatin, whereas those with a $B R C A$ mutational signature and no germline variant did not respond [109]. More clinical evaluations are needed to understand the impact of mutational signatures and response to therapeutic targets. 


\section{Gene expression signatures}

The most advanced use of gene signatures is gene expression profiling from RNA sequencing (RNAseq), gene expression microarrays, or other single-molecule enumeration methods that are used to subclassify tumors into gene expression signatures. For example, gene expression arrays are used to provide consensus molecular subtyping of colorectal cancer [110]. Mutated signatures that suggest "BRCAness" in breast, ovarian, and prostate cancers predict response to PARP inhibitors [111, 112]. Single-molecule enumeration technologies can generate gene expression counts and have been used in many disease sites to characterize expression signatures. Examples include additional subgroups of diffuse large B cell lymphoma and also a prognostic prediction of disease recurrence in breast cancer [113, 114]. Numerous other breast cancer recurrence risk testing platforms that use expression signatures are also available and incorporated into clinical practice guidelines [115]. These studies highlight the improved clinical sensitivity of gene expression signatures relative to single gene mutation testing, as many mutated signature profiles did not have a canonical mutation found in the respective gene. The detection of gene expression networks and of the activity of oncogenic pathways through transcriptomic analyses can add a more "functional" tumor profiling that can ultimately increase treatment opportunities [116]. The Worldwide Innovative Network (WIN) Consortium recently evaluated the feasibility and clinical utility of adding transcriptomic analysis to tumor genotyping (WINTHER study) [117]. In this study, patients were first evaluated for targetable alterations in cancer driver genes; if none were present, the patients received treatment tailored to differences in gene expression between the patients' tumor and normal tissue. The study showed that the addition of transcriptomic analysis to genomics increased actionability, with $35 \%$ of patients receiving matched targeted therapies. Overall, the efficacies of transcriptome-matched drugs appeared similar when compared with those of genotypematched drugs, with responses ranging between 20 and $30 \%$ [117]. A similar study led by the German Consortium Group is now ongoing and may add more information in this regard; the workflow involves NGS and other omics technology, bioinformatics processing, validation of variants, and clinical evaluation at MTB to match patients to treatment [118].

\section{Role of epigenetics in precision medicine}

Epigenetic changes modify the genome in order to modulate transcriptional activity that ultimately generates a permissive or restrictive architecture for cell growth and proliferation [119]. The epigenetic changes include the methylation of CpG islands in promoter regions, histone acetylation, and the association of non- coding RNA molecules (e.g., microRNA) with promoter regions. These epigenetic modifications can be detected using numerous technologies, including bisulfite sequencing, methylation microarrays, and chromatin immunoprecipitation sequencing arrays. Although many oncogenic targets of epigenetic pathways still rely on the detection of classic mutations found in genes that are involved in epigenetic modifications, such as DNMT and EZH2, genome-wide epigenetic maps of DNA methylation and histone modifications are being developed (e.g., International Human Epigenetic Consortium or NIH roadmap Epigenomics Mapping Consortium) [120, 121]. These epigenetic mapping efforts aim to help to granulate tumor biology and therapeutic potential for clinical action. Emerging data describing the role of epigenetic changes in oncogenesis and cancer progression pave the way for early therapeutic intervention or pharmacological targeting. For example, in pre-invasive lung cancer lesions, DNA methylation profiles are distinct between progressors and regressors [122]. Simultaneous mutations in IDH2 and SRSF2 genes promote leukemogenesis through coordinated effects on the epigenome and RNA splicing [123]. Genome-scale DNA methylation mapping demonstrates heterogeneity in time and space between primary and recurrent glioblastoma [124]. High and low CpG island methylator phenotypes in colorectal cancer are associated with $B R A F$ mutations or KRAS mutations, respectively [125]. Although epigenetic targeting as a precision medicine strategy is complex and requires prospective clinical evaluation, the accumulating knowledge in this area will increase its therapeutic potential over time.

\section{Integration of PCM in the 10 era}

Beyond the protein expression of immune checkpoint molecules such as PD-L1, genomic analyses also play a role in predicting response or resistance to IO agents [126]. Tumor mutation burden (TMB), defined as the total number of coding mutations in the tumor genome, has emerged as a promising predictive biomarker of response to anti-PD-1/ PD-L1 agents in several prospective trials, which have included multiple tumor types [127-129]. TMB can be assessed either on tumor samples or using ctDNA from blood samples [130, 131]. However, the cutoff values and the size and content of the genomic footprint required for TMB analysis are still not clear [132], and harmonization initiatives are underway to standardize the approach to interpreting tumor mutation for therapeutic uses (e.g., Friends of Cancer TMB initiative Quality Assurance Initiative Pathology) [133]. TMB is not predictive of response to anti-PD-1/PD-L1 agents across all cancers, as a few tumor types, such as Merkel cell carcinomas, are quite responsive to IO agents despite having a relatively low TMB $[134,135]$. The presence of genomic aberrations affecting specific immune signaling pathways or genes that will ultimately lead to immune dysregulation (e.g., loss-of-function mutations in 
beta-2 microglobulin (B2M) or human leukocyte antigen (HLA) genes, PTEN loss, or mutations in JAK or other IFN $\gamma$-related genes) can be informative of resistance to immune checkpoint inhibitors [126, 136-138]. In addition to genomics, transcriptomic analyses can be used to define gene expression profile signatures that can be used to identify tumors that are more likely to respond to IO agents. For example, a "T cell-inflamed" gene expression profile was recently shown to be predictive of response to anti-PD-1/ PD-L1 agents, regardless of tumor type [127].

\section{Evolving scope of precision cancer medicine}

The field of precision oncology is moving from isolated genomic analyses towards a multi-omic approach to achieve a better understanding of tumor biology and to increase treatment opportunities. The ACNS02B3 brain tumor biology study, led by the Children's Oncology Group across several institutions, represents a successful example of expanding molecular profiling beyond genomics. In this study, five distinct tumor molecular subgroups were identified on the basis of IHC, genomics, epigenetics, and transcriptomic analyses, which were reproducible in patient-derived xenograft models and thus allowed for in vivo drug sensitivity tests [139]. Beyond single gene analyses, mutational signatures, RNAbased gene expression profiling, immunophenotyping, and TMB determination have proven to be useful prognostic and predictive biomarkers of response to anticancer therapies, but whether they will lead to an increase in treatment opportunities is still unclear. The application of molecular profiling results in the clinical setting still faces several challenges. Current pitfalls and potential solutions are discussed below.

\section{Challenges and solutions for clinicians acting on molecular profiling results}

Tremendous progress has been made in the field of precision medicine, with ever-increasing numbers of patients being tested and new biomarkers being developed leading to expanded therapeutic opportunities, but challenges remain. The results from target-drug matching initiatives have been disappointing to date, as most of these have matching rates of only $5-10 \%$ and the objective responses in genotype-matched patients have been modest (less than 20\%; Table 2) [24-27, 96-98, 140-142]. There are multiple reasons for these low rates and the lack of objective responses in many genotype-matched patients. For instance, the disease may have progressed during the wait for sequencing results so that the patient is no longer fit for treatment, best-in-class therapeutic agents are not always available, poor response to a targeted agent may occur despite matching, there may be intratumoral heterogeneity, the treatment may be targeting a non-driver or passenger mutation, and there may be difficulties in combining targeted agents because of toxicity [143]. The systematic charting of successful and unsuccessful molecular treatment indications is still in its early stages. Efforts at data collection and sharing in order to provide evidence linking biomarkers to drugs and/or tumor types are required and need to be made public to guide treatment decision. For example, it has recently been shown that germline or somatic loss-of-function alterations in $B R C A 1 / 2$ are associated with tumorigenesis in only a few types of cancer, namely breast, ovarian, prostate, and pancreatic cancers, and that there is little benefit in treating other cancer types that harbor such mutations with PARP inhibitors [144].

Multiple surveys have been undertaken to assess the utility of molecular profiling in patient care, and some of the issues identified that can limit access to potential treatment options include poor access to targeted agents, cost of targeted agents, and lack of clinical trial availability [143]. Limitations to the full implementation of precision medicine in routine clinical practice include the complexity of the molecular information generated, uncertainty surrounding the clinical utility of the information, lack of knowledge about this framework in general among healthcare professionals, and the economic costs of the tests. The number of genes that

Table 2 Selected molecular profiling initiatives and genotype matching to clinical trials

\begin{tabular}{|c|c|c|c|c|c|c|}
\hline Group & Sample size & Platform & Tissue sample & Germline control & $\begin{array}{l}\text { Patients enrolled in } \\
\text { genotype-matched trials }\end{array}$ & $\begin{array}{l}\text { ORR of patients } \\
\text { matched to } \\
\text { treatment based } \\
\text { on genotype }\end{array}$ \\
\hline MSKCC [27] & 12,670 & 341-410 gene panels & FFPE & Yes & $527 / 5009(10.5 \%)$ & Not available \\
\hline DFCl-HCC [28] & 3727 & 275 gene panels & FFPE & No & $16 / 50(32 \%)$ & Not available \\
\hline Lyon $[140,141]$ & 2579 & 69 gene panels $+\mathrm{aCGH}$ & FFPE & Yes & 182/2579 (7\%) & $13 \%$ \\
\hline MDACC [26] & 2000 & 11-50 gene panels & FFPE & No & $83 / 2000$ (4.2\%) & Not available \\
\hline Princess Margaret [25] & 1640 & 23-48 gene panels & FFPE & Yes & $92 / 1640(5.6 \%)$ & $19 \%$ \\
\hline Goustave Roussy [24] & 1035 & 30-75 gene panels $+\mathrm{aCGH}$ & Fresh biopsy & Yes & 199/1035 (19.2\%) & $11 \%$ \\
\hline Michigan [142] & 556 & WGS, WES, RNASeq & Fresh biopsy & Yes & $3-11 \%$ & Not available \\
\hline
\end{tabular}

aCGH array comparative genomic hybridization, DFCI-HCC Dana Farber Cancer Institute-Harvard Cancer Center, FFPE formalin-fixed paraffin-embedded, MDACC MD Anderson Cancer Center, MSKCC Memorial Sloan Kettering Cancer Center, ORR objective response rate, WES whole exome sequencing, WGS whole genome sequencing 
can be sequenced is very large, but not all of the genes will have practical application.

\section{Clinician education}

Although large gene panel testing is being incorporated into clinical care, hurdles exist that may limit the applications of NGS by healthcare professionals to levels below their maximum potential. For instance, it has been shown that the results can be difficult to interpret, leading to the under- or over-interpretation of genomic information $[145,146]$. The provision by clinical laboratories of NGS reports that include features such as a succinct summary of the genomic findings, written for a non-genetic specialist audience, will help with the decision-making process $[147,148]$. A sample genomic report with information from a variety of resources can be seen in Table 3, which illustrates some of the challenges that face clinicians when interpreting annotations from different knowledgebases that are available for specific mutations. These challenges can include a lack of information regarding how a particular mutation or conflicting information from different knowledgebases should be interpreted. The development of easily accessible online genomic knowledge banks provides resources to aid data interpretation and clinical decision-making. Treating oncologists frequently cite perceived low levels of genetic knowledge or limited confidence in their ability to interpret genomic reports as reasons for lower utilization of genetic testing [151]. Several large institutions have created teams to centralize genomic interpretation and provide decision support. As an example, the Precision Oncology Decision Support (PODS) platform provides clinical decision support for oncologists at the MD Anderson Cancer Center. PODS offers a rapid and easily accessible means of obtaining scientifically curated information about the functional effects of genetic alterations, as well as information on genotype-matched therapeutics (including clinical trials) that are relevant to their patients [152, 153].

With a longer vision, it will be important to educate future physicians and expose medical students to this growing area. Specialist medical oncology training should also involve a focus on precision medicine, and physicians should be encouraged to become actively involved in MTB. Continuing medical education training courses should provide a focus on precision medicine, and ensuring that there is adequate staffing in terms of genetic counselors, medical geneticists, and adequately trained physicians in this field is essential.

\section{Patient education}

Another aspect of genomic healthcare involves the education of patients in order to facilitate their taking part in their own care. A significant proportion of the general public have difficulty in understanding health and specifically genetic information. There is a need for educational intervention research to help patients to understand test results and treatment options. As many patients are eager to undergo tumor sequencing, providers need to communicate its potential benefits as well as its risks and limitations clearly. Patients have high expectations for and interest in tumor sequencing, but they can be concerned about the complexity of the data, the potential for disappointment, and the loss of hope after testing (especially if no alterations are identified). The education of patients prior to testing is essential, but how best to execute this is unknown [154]. A helpful step in terms of improving patient engagement with their own care is the development of patient-friendly reports and patient-specific webpages, written in an accessible language in the knowledgebases being used by physicians. An important aspect of patient education in precision medicine surrounds the potential for the identification of secondary germline mutations and the potential to assess the patient's preference for receiving incidental germline findings [155]. Studies indicate that up to $18 \%$ of patients undergoing tumor-normal sequencing have a pathogenic germline variant [156-158]. In addition, many providers may not feel qualified or have the time to have a discussion with their patients regarding secondary germline findings. Access to genetic counselors can be challenging in a community setting [159]. As a result, the development of virtual or telehealth genetic counseling support may be worth exploring. The COMmunication and Education in Tumor profiling (COMET) study, which is an ancillary study to NCI-MATCH, aims to examine whether educating patients who have cancer about genetic testing will increase their knowledge and reduce stress levels after receiving the results of tumor profiling [160].

\section{Increased trial opportunities}

Traditional clinical trial designs may not offer an efficient investigation of precision medicine, and as a result, more flexible trial designs have been developed. Adaptive studies include inbuilt opportunities to modify one or more specified trial elements on the basis of intermediate data analysis. For instance, treatment arms may be opened or closed on the basis of provisional findings at pre-specified points, such as emerging evidence of response to treatment. This can increase efficiency by facilitating the selection of the dose, sparing patients from being exposed to ineffective doses, and reducing cost and duration of clinical development [161]. The evolution of the use of genomic results to guide treatment decisions in precision medicine has led to the increased use of "master protocols" or "platform trials," in which multiple parallel studies operate under one overarching protocol. These platforms, developed to allow the investigation of multiple target-treatment pairs in parallel, require close collaboration between industry, academic, and regulatory partners. As an example, the CAnadian Profiling 
Table 3 Sample genomic report with several mutations of interest, which have varying degrees of actionability. Key information available through the CIViC $[78,149]$ and OncoKB $[77,150]$ databases for each variant is displayed in the table below the example report. The details of the CIViC variant evidence score [78, 149] and The OncoKB level of evidence system [77, 150] are available in the literature and on the relevant websites. Column 4 of the table displays the respective tier that the mutation falls into based on the AMP/ASCO classification for the interpretation of sequence variants in cancer [86]
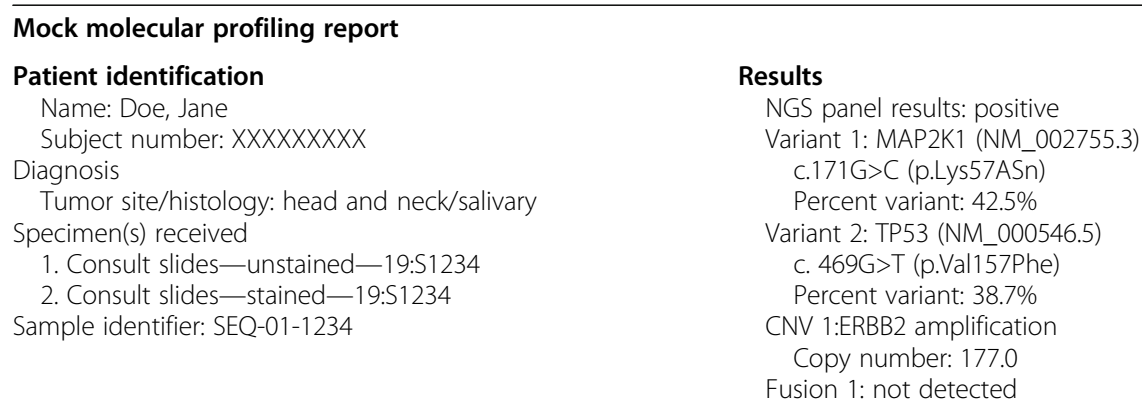

\section{Methodology}

Genomic DNA and RNA was extracted and analyzed using an NGS Panel that examines the coding regions ( \pm 10 bp) of 500 genes using target enrichment hybrid capture followed by paired-end sequencing on the next sequencing platform. Variant calls are generated using a custom bioinfor matics pipeline with alignment to genome build GRCh37/hg19. Minimum acceptable coverage for all reported genomic regions is $>200$. The reportable range is 10-100\% variant allele frequency. Test sensitivity is $>98 \%$ for detection of substitutions, small insertions or deletions, copy number changes, and RNA fusions. Large insertions or deletions, gene amplifications or loss, and some fusions may not be detected by this assay. Variants are interpreted only as somatic tumor variants because testing of DNA from germline tissue was not performed. Current methods may not detect all of the variants present in the genes tested.

\section{Interpretation}

Variant

CIViC database $[78,149]$

OncoKB database $[77,150]$

$\begin{array}{ll}\text { MAP 2 K1 } & \text { MAP2K1 is a dual-specificity kinase involved } \\ \text { (NM_ } & \text { in the ERK pathway. Activating mutations } \\ 002755.3) & \text { have been seen in ovarian, melanoma, and } \\ \text { c.171G>C } & \text { lung cancers. Inhibitors of MEK genes have } \\ \text { (p.Lys57ASn) } & \begin{array}{l}\text { been shown to inhibit tumor growth. } \\ \text { Evidence for K57N: } 2 \text { references }\end{array} \\ & \text { This variant does not have a specific summary } \\ & \text { page } \\ & \text { Variant type: missense } \\ & \text { CIViC variant evidence score: } 9.5 \\ & \text { Drugs: selumetinib }\end{array}$

TP53 (NM TP53 mutations are universal across cancer 000546.5) types. Majority of mutations localize to the c. $469 \mathrm{G}>\mathrm{T} \quad$ DNA binding domain

(p.Val157Phe) Evidence for DNA binding mutation: 2 references

Variant type: DNA binding site

CIViC variant evidence score: 35

Drugs: none

ERBB2 ERBB2/HER-2 is amplified or overexpressed

amplification in $20-30 \%$ of invasive breast cancers, commonly treated with HER-2 targeted therapy. Evidence for amplification: 60 references Variant type: transcript amplification CIViC variant evidence score: 822.5 Drugs: trastuzumab, pertuzumab, neratinib, lapatinib, TDM-1, afatinib, cetuximab

High TMB No specific reference page

Level of evidence: $3 \mathrm{~A}$
Oncogenic: yes

Mutation effect: gain-of-function

Citations: 4 references

Cancer type: low-grade serous ovarian cancer, melanoma, non-small cell lung cancer, histiocytosis

Drugs: cobimetinib, trametinib

Oncogenic: likely

Mutation effect: likely loss-of-function

Citations: 3 references

Level of evidence: N/A

\section{Oncogenic: yes}

Mutation effect: gain-of-function

Citations: 6 references

Cancer types: breast cancer,

esophagogastric cancer, uterine serous carcinoma

Drugs: lapatinib, trastuzumab, TDM-1, neratinib, pertuzumab

Level of evidence: $2 B$
Drugs: none

Standards and guidelines for the interpretation and reporting of sequence variants in cancer [86]

Tier IID_-potential clinical significance Preclinical trials: few case reports without consensus

- Rare in the head and neck (TCGA)

- Gain-of-function variant

Tier IID—potential clinical significance Preclinical trials: few case reports without consensus

- Non-functional variant (IARC TP53 database)

- Seen in the head and neck (TCGA, COSMIC)

Tier IIC—-potential clinical significance. FDA-approved therapy for different tumor site

- ERBB2 inhibitors used in metastatic breast cancer

- ERBB2 amplifications seen in head and neck (TCGA, COSMIC)

Not approved for head and neck tumors No specific reference page

No suitable category and Targeted agent Utilization Trial (CAPTUR) [162] involves collaboration between pharmaceutical companies, Health Canada, the Canadian Clinical Trials Group
(CCTG), and the individual health care facilities involved in running the study. Logistics can often be complicated, requiring multiple pharmaceutical companies to provide 
drugs to a trial. Basket trials test the effect of one drug on a single aberration in a variety of tumor types, greatly increasing the number of patients who are eligible to receive certain drugs. Conversely, in umbrella studies, patients with a specific cancer type are centrally screened and assigned to one of several molecularly defined subtrials investigating a matched targeted therapy. These trials are relatively flexible and allow for the addition of new treatment arms as new clinical data become available [163, 164].

A number of basket trials around the world are currently recruiting patients, some of which are highlighted in Table 4 . These trials are testing commercially available targeted agents (and in some cases also investigational agents) in patients who have undergone tumor profiling. The results from three cohorts of one of these studies, the NCIMATCH study, have been reported: patients with ERRB2/ HER2 amplification [168], FGFR alterations [169], or PIK3CA [170] mutations were treated with T-DM1, AZD4547, or taselisib, respectively. Unfortunately, objective response rates were low in all three groups, ranging from 0 to $9.5 \%$. Reasons that might account for these low responses include that the patients were heavily pre-treated or the presence of co-occurring mutations. Numerous umbrella protocol studies are ongoing, one example being the Adjuvant Lung Cancer Enrichment Marker Identification and Sequencing Trials (ALCHEMIST), which is investigating the use of targeted therapy in patients with resectable adenocarcinoma of the lung with EGFR mutation or $A L K$ translocation after completion of standard therapy [171].

The Drug Rediscovery Protocol (DRUP) is an ongoing Dutch adaptive precision oncology trial that facilitates the use of approved drugs beyond their approved indication in rare cancer subgroups. Initial results from the two subgroups that have completed data accrual have been published. The first was in agnostic microsatellite instable (MSI) tumors treated with nivolumab. The European Medicines Agency has not yet approved the use of checkpoint inhibitors in this setting, but on the basis of the positive results from DRUP, the Dutch regulatory agency has now approved the use of these drugs in this indication. The second cohort in microsatellite stable colorectal cancer with TMB between 11 and 22 mutations per megabase showed limited clinical benefit, leading to the closure of the arm [39, 167, 172].

By and large, current platform trials are exploring targeted agents given as monotherapies. Genomic alterations do not always lead to oncogenic pathway activation or addiction, whereby certain tumor cells become dependent on a single activated oncogenic protein or pathway. As a result, targeting of multiple driver and/or resistance pathways using combinatorial approaches may be required for optimal antitumor activity [173]. The iPREDICT study is matching patients to combination therapies on the basis of genomic results interpreted by the study's MTB. Initial results from 73 patients treated with bespoke personalized therapy showed that $30 \%$ of the patients achieved disease control. As many of the combinations had not been tested for safety, patients were initially started on low doses of the drugs, which were increased to a level that was well tolerated by each patient [174].

\section{Trial matching resources}

Numerous components are involved in automating the matching of patients to clinical trials, including creating a database and then establishing a method to search the database to match patients to trials. In addition, the maintenance of up-to-date comprehensive databases is necessary for the automation of patient-trial matching [175]. The Phase One Spot Tracker (POST) is an online secure database that has been set up in Princess Margaret Cancer Centre. This database contains key trial eligibility criteria and can be used to help to identify patients for trials on the basis of their tumor type and molecular signature (https://uhnddp.ca) [176]. Furthermore, Matchminer, developed by the Dana Farber Cancer Institute, is an example of an open-source computational platform that matches patient-specific genomic events to clinical trials and makes the results available to trial investigators and clinicians via a web-based platform [177]. The use of artificial intelligence to improve the matching of patients to trials has also been investigated. For instance, the Watson for Clinical Trial Matching cognitive system uses natural language processing to derive patient and tumor attributes from electronic health records and to match the data to clinical trial eligibility criteria. This platform has been found to increase clinical trial enrollment of breast cancer patients [178].

\section{Conclusions}

The implementation of precision medicine through molecular profiling technologies has increasingly been integrated with standard clinicopathological evaluations to enhance diagnosis, prognostication, and prediction of clinical outcomes. Although there have been clear successes in the era of molecular characterization, the utility of NGS and other omics-based tests remains unproven on many fronts. A vision for the future of precision medicine will integrate comprehensive multi-omic tumor characterization, dynamic monitoring of liquid biopsy samples, annotation that is automated through advancements in artificial intelligence but guided by experts' clinical input, the enrollment of patients into innovative clinical trials that not only test molecular profile-drug matching but also investigate the utility of different drug-assignment algorithms [179], and the realtime addition of information from each case to global knowledgebases to enhance precision cancer medicine learning. The path forward in precision medicine will 
Table 4 Selected examples of ongoing large genotype-drug matching PCM trials

\begin{tabular}{|c|c|c|c|c|}
\hline Name & Site & Sample size & Mutations matched & Targeted drugs used \\
\hline \multirow[t]{25}{*}{ NCI-MATCH [165] } & \multirow{25}{*}{$\begin{array}{l}\text { National Cancer } \\
\text { Institute (NCl) }\end{array}$} & \multirow[t]{25}{*}{6452} & EGFR/HER2-activating mutation & Afatinib \\
\hline & & & MET, ALK, ROS1 & Crizotinib \\
\hline & & & EGFR T790M or other activating mutation & Osimertinib \\
\hline & & & $\begin{array}{l}\text { BRAF V600E/R/K/D, BRAF fusion, non-BRAF } \\
\text { V600 mutations }\end{array}$ & Dabrafenib+trametinib \\
\hline & & & NF1, GNAQ, GNA11 & Trametinib \\
\hline & & & PIK3CA & Taselisib \\
\hline & & & HER-2 amplification & Trastuzumab+pertuzumab \\
\hline & & & FGFR mutation or fusion & Erdafitinib \\
\hline & & & mTOR, TSC1, TSC2 & Sapanisertib \\
\hline & & & PTEN mutation & GSK2636771 (PI3K beta inhibitor) \\
\hline & & & HER-2 amplification & Trastuzumab, emtansine \\
\hline & & & SMO, PTCH1 & Vismodegib \\
\hline & & & NF2 inactivating mutation & Defactinib \\
\hline & & & CKIT mutation & Sunitinib \\
\hline & & & FGFR1, FGFR2, FGFR3 mutation & AZD4547 (FGFR inhibitor) \\
\hline & & & Certain DDR2 mutations & Dasatinib \\
\hline & & & AKT mutation & Capivasertib \\
\hline & & & NRAS mutations & Binimetinib \\
\hline & & & CDK4, CDK6 & Palbociclib \\
\hline & & & Mismatch repair deficiency & Nivolumab \\
\hline & & & NTRK1, NTRK2, NTRK3 fusions & Larotrectinib \\
\hline & & & PIK3CA, PTEN mutations & Copanlisib \\
\hline & & & BRCA1, BRCA2 mutation & Adavosertib \\
\hline & & & AKT mutation & Ipatasertib \\
\hline & & & BRAF non-V600 mutation or BRAF fusion & Ulixertinib \\
\hline \multirow[t]{12}{*}{ TAPUR [166] } & \multirow{12}{*}{$\begin{array}{l}\text { American Society } \\
\text { of Clinical } \\
\text { Oncology (ASCO) }\end{array}$} & \multirow[t]{12}{*}{3123} & ALK, ROS1, MET & Crizotinib \\
\hline & & & CDKN2A, CDK4, CDK6 & Palbociclib \\
\hline & & & CSF1R, PDGFR, VEGFR & Sunitinib \\
\hline & & & mTOR, TSC & Temsirolimus \\
\hline & & & ERBB2 & Trastuzumab+pertuzumab \\
\hline & & & BRAFV600E/D/K/R & Vemurafenib+cobimetinib \\
\hline & & & NRAS, KRAS, NRAF & Cetuximab \\
\hline & & & $\begin{array}{l}\text { BCR-ABL, SRC, KIT, PDGFRB, EPHA2, FYN, } \\
\text { LCK, YES1 }\end{array}$ & Dasatinib \\
\hline & & & RET, VEGFR1/2/3, KIT, PDGFRB, RAF-1, BRAF & Regorafenib \\
\hline & & & BRCA1, BRCA2, ATM & Olaparib \\
\hline & & & POLE, POLD1, high mutational load & Pembrolizumab \\
\hline & & & MSI-high, high mutational load and others & Nivolumab+ipilimumab \\
\hline \multirow[t]{6}{*}{ CAPTUR [162] } & \multirow{6}{*}{$\begin{array}{l}\text { Canadian Cancer } \\
\text { Trials Group (CCTG) }\end{array}$} & \multirow[t]{6}{*}{720} & VEGFR1, VEGFR2, VEGFR2 & Axitinib \\
\hline & & & BCR-ABL, SRC & Bosutinib \\
\hline & & & ALK, ROS1, MET & Crizotinib \\
\hline & & & KIT, PDGRFA, PDGFRB, ABL1 & Dasatinib \\
\hline & & & EGFR & Erlotinib \\
\hline & & & High mutation burden, POLE, POLD1 & Nivolumab+ipilimumab \\
\hline
\end{tabular}


Table 4 Selected examples of ongoing large genotype-drug matching PCM trials (Continued)

\begin{tabular}{|c|c|c|c|c|}
\hline Name & Site & Sample size & Mutations matched & Targeted drugs used \\
\hline & & & BRCA1, BRCA2, mutations in HRD & Olaparib \\
\hline & & & CDKN2A, CDK4, CDK6, CCND1 & Palbociclib \\
\hline & & & $\begin{array}{l}\text { CSF1R, PDGFRA, PDGFRB, VEGFR1, VEGFR2, } \\
\text { VEGFR3, KIT, FLT3, RET, FGFR1, FGFR2, } \\
\text { FGFR3, VHL }\end{array}$ & Sunitinib \\
\hline & & & $\begin{array}{l}\text { AKT1, AKT2, AKT3, FBXW7, FLCN, mTOR, } \\
\text { NF1, NF2, NTRK3, PIK3CA, PIK3R1, PTEN, } \\
\text { RHEB, STKII, TSC1, TSC2 }\end{array}$ & Temsirolimus \\
\hline & & & ERBB2 & Trastuzumab+pertuzumab \\
\hline & & & BRAFV600 & Vemurafenib+cobimetinib \\
\hline & & & PTCH1, SMO & Vismodegib \\
\hline \multirow[t]{11}{*}{ DRUP [167] } & \multirow{11}{*}{$\begin{array}{l}\text { Netherlands } \\
\text { Cancer Institute }\end{array}$} & \multirow[t]{11}{*}{400} & KRAS, BRAF, NRAS wild type & Panitimumab \\
\hline & & & BRCA1, BRCA2, ATM & Olaparib \\
\hline & & & BRAF & Dabrafenib \\
\hline & & & $\begin{array}{l}\text { Molecular profile that can potentially be } \\
\text { targeted by nilotinib }\end{array}$ & Nilotinib \\
\hline & & & $\begin{array}{l}\text { Molecular profile that can potentially be } \\
\text { targeted by trametinib }\end{array}$ & Trametinib \\
\hline & & & $\begin{array}{l}\text { Molecular profile that can potentially be } \\
\text { targeted by erlotinib }\end{array}$ & Erlotinib \\
\hline & & & $\begin{array}{l}\text { HER-2 overexpression, amplification or } \\
\text { mutated }\end{array}$ & Trastuzumab+pertuzumab \\
\hline & & & BRAF mutated tumors & Vemurafenib+cobimetinib \\
\hline & & & $\begin{array}{l}\text { Molecular profile that can potentially be } \\
\text { targeted by vismodegib }\end{array}$ & Vismodegib \\
\hline & & & $\begin{array}{l}\text { Molecular profile that can potentially be } \\
\text { targeted by regorafenib }\end{array}$ & Regorafenib \\
\hline & & & $\begin{array}{l}\text { Molecular profile that can potentially be } \\
\text { targeted by nivolumab }\end{array}$ & Nivolumab \\
\hline
\end{tabular}

require not only extension beyond genomics from a technical viewpoint, but also the education and engagement of end-users such as clinicians and patients, the increase of access to genotype-drug matching through adaptive and other innovative clinical trial designs, and the promotion of data sharing to maximize knowledge gain.

\section{Supplementary information}

Supplementary information accompanies this paper at https://doi.org/10. 1186/s13073-019-0703-1.

Additional file 1. Advantages and disadvantages of NGS-based approaches.

\section{Abbreviations}

CNV: Copy number variations; CTC: Circulating tumor cell; ctDNA: Circulating tumor DNA; FISH: Fluorescence in situ hybridization;

IHC: Immunohistochemistry; IO: Immuno-oncology; miRNA: MicroRNA; MTB: Molecular tumor board; NGS: Next-generation sequencing; NSCLC: Nonsmall cell lung cancer; SNV: Single nucleotide variants; TCGA: The Cancer Genome Atlas; TMB: Tumor mutation burden; WES: Whole exome sequencing; WGS: Whole genome sequencing

\section{Acknowledgements}

LLS holds the BMO Chair in Precision Cancer Genomics.

\section{Authors' contributions}

All authors contributed to the research and to the writing of this manuscript, and all approved the final version.

\section{Funding}

This work was not funded by any specific grants from agencies in the public, commercial, or not-profit sectors.

\section{Competing interests}

LLS is a consultant for Merck (compensated), Pfizer (compensated), Celgene (compensated), AstraZeneca/Medimmune (compensated), Morphosys (compensated), Roche (compensated), GeneSeeq (compensated), Loxo (compensated), Oncorus (compensated), Symphogen (compensated), Seattle Genetics (compensated), GSK (compensated), Voronoi (compensated), and Treadwell Therapeutics (compensated). She has received grants or research support from Novartis, Bristol-Myers Squibb, Pfizer, Boehringer-Ingelheim, GlaxoSmithKline, Roche/Genentech, Karyopharm, AstraZeneca/Medimmune, Merck, Celgene, Astellas, Bayer, Abbvie, Amgen, Symphogen, Intensity Therapeutics, Mirati, Shattucks, and Avid. Her spouse holds stock in Agios. $\mathrm{MO}$ is a consultant for Bristol-Myers Squibb (compensated).

TLS is a consultant for Astra Zeneca, Amgen, Astellas, Janssen, and Bristol Myers Squibb.

The remaining authors declare that they have no competing interests. 


\section{Author details}

'Division of Medical Oncology and Hematology, Princess Margaret Cancer Centre, University Health Network, Department of Medicine, University Avenue, University of Toronto, Toronto, Ontario M5G 1Z5, Canada. ${ }^{2}$ Department of Clinical Laboratory Genetics, University Health Network, and Department of Laboratory Medicine and Pathobiology, University of Toronto, Toronto, Canada.

\section{Received: 20 September 2019 Accepted: 4 December 2019}

\section{Published online: 14 January 2020}

\section{References}

1. Yates LR, Seoane J, Le Tourneau C, Siu LL, Marais R, Michiels S, et al. The European Society for Medical Oncology (ESMO) precision medicine glossary. Ann Oncol. 2018:29:30-5.

2. FDA. Novel drug approvals for 2019. https://www.fda.gov/drugs/new-drugsfda-cders-new-molecular-entities-and-new-therapeutic-biological-products/ novel-drug-approvals-2019. Accessed 21 Nov 2019

3. European Medicines Agency. List of EMA-approved medicines. https://www. ema.europa.eu/en/medicines/field_ema_web_categories\%253Aname_field/ Human. Accessed 21 Nov 2019.

4. Dietel M, Johrens $\mathrm{K}$, Laffert MV, Hummel M, Blaker $\mathrm{H}$, Pfitzner BM, et al. A 2015 update on predictive molecular pathology and its role in targeted cancer therapy: a review focussing on clinical relevance. Cancer Gene Ther. 2015;22:417-30.

5. Lindeman NI, Cagle PT, Beasley MB, Chitale DA, Dacic S, Giaccone G, et al. Molecular testing guideline for selection of lung cancer patients for EGFR and ALK tyrosine kinase inhibitors: guideline from the College of American Pathologists, International Association for the Study of Lung Cancer, and Association for Molecular Pathology. Arch Pathol Lab Med. 2013;137:828-60.

6. Yoshida A, Tsuta K, Wakai S, Arai Y, Asamura H, Shibata T, et al. Immunohistochemical detection of ROS1 is useful for identifying ROS1 rearrangements in lung cancers. Mod Pathol. 2014;27:711-20.

7. Reuss DE, Sahm F, Schrimpf D, Wiestler B, Capper D, Koelsche C, et al. ATRX and IDH1-R132H immunohistochemistry with subsequent copy number analysis and IDH sequencing as a basis for an "integrated" diagnostic approach for adult astrocytoma, oligodendroglioma and glioblastoma. Acta Neuropathol. 2015;129:133-46.

8. Patel SP, Kurzrock R. PD-L1 expression as a predictive biomarker in cancer immunotherapy. Mol Cancer Ther. 2015;14:847-56.

9. Chang L, Chang M, Chang HM, Chang F. Microsatellite instability: a predictive biomarker for cancer immunotherapy. Appl Immunohistochem Mol Morphol. 2018;26:e15-21.

10. Pai-Scherf L, Blumenthal GM, Li H, Subramaniam S, Mishra-Kalyani PS, He K, et al. FDA approval summary: pembrolizumab for treatment of metastatic non-small cell lung cancer: first-line therapy and beyond. Oncologist. 2017; 22:1392-9.

11. Thunnissen E, Bubendorf L, Dietel M, Elmberger G, Kerr K, Lopez-Rios F et al. EML4-ALK testing in non-small cell carcinomas of the lung: a review with recommendations. Virchows Arch. 2012;461:245-57.

12. Lateef $F$, Jamal $S$, Nasir $S$. Her-2/neu oncogene amplification by fluorescence in situ hybridization and protein overexpression on immunohistochemistry in breast cancer. J Coll Physicians Surg Pak. 2018;28:581-5.

13. Yang Z, Hackshaw A, Feng Q, Fu X, Zhang Y, Mao C, et al. Comparison of gefitinib, erlotinib and afatinib in non-small cell lung cancer: a metaanalysis. Int J Cancer. 2017;140:2805-19.

14. Poveda A, Garcia Del Muro X, Lopez-Guerrero JA, Cubedo R, Martinez V, Romero I, et al. GEIS guidelines for gastrointestinal sarcomas (GIST). Cancer Treat Rev. 2017:55:107-19.

15. Chapman PB, Hauschild A, Robert C, Haanen JB, Ascierto P, Larkin J, et al. Improved survival with vemurafenib in melanoma with BRAF V600E mutation. N Engl J Med. 2011;364:2507-16.

16. Lievre A, Bachet JB, Le Corre D, Boige V, Landi B, Emile JF, et al. KRAS mutation status is predictive of response to cetuximab therapy in colorectal cancer. Cancer Res. 2006;66:3992-5.

17. Moorcraft SY, Gonzalez D, Walker BA. Understanding next generation sequencing in oncology: a guide for oncologists. Crit Rev Oncol Hematol. 2015;96:463-74.

18. Hinrichs JW, van Blokland WT, Moons MJ, Radersma RD, Radersma-van Loon JH, de Voijs CM, et al. Comparison of next-generation sequencing and mutationspecific platforms in clinical practice. Am J Clin Pathol. 2015;143:573-8.
19. Misyura M, Zhang T, Sukhai MA, Thomas M, Garg S, Kamel-Reid S, et al. Comparison of next-generation sequencing panels and platforms for detection and verification of somatic tumor variants for clinical diagnostics. J Mol Diagn. 2016:18:842-50.

20. Sie D, Snijders PJ, Meijer GA, Doeleman MW, van Moorsel MI, van Essen HF, et al. Performance of amplicon-based next generation DNA sequencing for diagnostic gene mutation profiling in oncopathology. Cell Oncol (Dordr). 2014;37:353-61.

21. Su D, Zhang D, Chen K, Lu J, Wu J, Cao X, et al. High performance of targeted next generation sequencing on variance detection in clinical tumor specimens in comparison with current conventional methods. J Exp Clin Cancer Res. 2017;36:121.

22. Yip S, Christofides A, Banerji S, Downes MR, Izevbaye I, Lo B, et al. A Canadian guideline on the use of next-generation sequencing in oncology. Curr Oncol. 2019:26:e241-54.

23. Hartmaier RJ, Charo J, Fabrizio D, Goldberg ME, Albacker LA, Pao W et al. Genomic analysis of 63,220 tumors reveals insights into tumor uniqueness and targeted cancer immunotherapy strategies. Genome Med. 2017;9:16.

24. Massard C, Michiels S, Ferte C, Le Deley MC, Lacroix L, Hollebecque A, et al. High-throughput genomics and clinical outcome in hard-to-treat advanced cancers: results of the MOSCATO 01 trial. Cancer Discov. 2017;7:586-95.

25. Stockley TL, Oza AM, Berman HK, Leighl NB, Knox JJ, Shepherd FA, et al. Molecular profiling of advanced solid tumors and patient outcomes with genotype-matched clinical trials: the Princess Margaret IMPACT/COMPACT trial. Genome Med. 2016;8:109.

26. Meric-Bernstam F, Brusco L, Shaw K, Horombe C, Kopetz S, Davies MA, et al. Feasibility of large-scale genomic testing to facilitate enrollment onto genomically matched clinical trials. J Clin Oncol. 2015;33:2753-62.

27. Zehir A, Benayed R, Shah RH, Syed A, Middha S, Kim HR, et al. Mutational landscape of metastatic cancer revealed from prospective clinical sequencing of 10,000 patients. Nat Med. 2017;23:703-13.

28. Sholl LM, Do K, Shivdasani P, Cerami E, Dubuc AM, Kuo FC, et al. Institutional implementation of clinical tumor profiling on an unselected cancer population. JCI Insight. 2016;1:e87062.

29. Le Tourneau C, Kamal M, Tsimberidou AM, Bedard P, Pierron G, Callens C, et al. Treatment algorithms based on tumor molecular profiling: the essence of precision medicine trials. J Natl Cancer Inst. 2015;108. https://doi.org/10. 1093/jnci/djv362.

30. Hess JM, Bernards A, Kim J, Miller M, Taylor-Weiner A, Haradhvala NJ, et al. Passenger hotspot mutations in cancer. Cancer Cell. 2019;36:288-301.

31. Presley CJ, Tang D, Soulos PR, Chiang AC, Longtine JA, Adelson KB, et al Association of broad-based genomic sequencing with survival among patients with advanced non-small cell lung cancer in the community oncology setting. JAMA. 2018;320:469-77.

32. Bollinger MK, Agnew AS, Mascara GP. Osimertinib: a third-generation tyrosine kinase inhibitor for treatment of epidermal growth factor receptormutated non-small cell lung cancer with the acquired Thr790Met mutation. J Oncol Pharm Pract 2018:24:379-88.

33. Robert C, Karaszewska B, Schachter J, Rutkowski P, Mackiewicz A, Stroiakovski D, et al. Improved overall survival in melanoma with combined dabrafenib and trametinib. N Engl J Med. 2015;372:30-9.

34. Soria JC, Ohe Y, Vansteenkiste J, Reungwetwattana T, Chewaskulyong B, Lee $\mathrm{KH}$, et al. Osimertinib in untreated EGFR-mutated advanced non-small-cell lung cancer. N Engl J Med. 2018:378:113-25.

35. Mok TS, Wu YL, Ahn MJ, Garassino MC, Kim HR, Ramalingam SS, et al. Osimertinib or platinum-pemetrexed in EGFR T790M-positive lung cancer. N Engl J Med. 2017;376:629-40.

36. Planchard D, Smit EF, Groen HJM, Mazieres J, Besse B, Helland A, et al. Dabrafenib plus trametinib in patients with previously untreated BRAF(V600E)-mutant metastatic non-small-cell lung cancer: an open-label, phase 2 trial. Lancet Oncol. 2017:18:1307-16.

37. Ettinger DS, Aisner DL, Wood DE, Akerley W, Bauman J, Chang JY, et al. NCCN guidelines insights: non-small cell lung cancer, version 5.2018. J Natl Compr Cancer Netw. 2018;16:807-21

38. Coit DG, Thompson JA, Algazi A, Andtbacka R, Bichakjian CK, Carson WE 3rd, et al. NCCN guidelines insights: melanoma, version 3.2016. J Natl Compr Cancer Netw. 2016:14:945-58.

39. Priestley P, Baber J, Lolkema MP, Steeghs N, de Bruijn E, Shale C, et al. Pan-cancer whole-genome analyses of metastatic solid tumours. Nature. 2019;575:210-6 
40. Ma X, Liu Y, Liu Y, Alexandrov LB, Edmonson MN, Gawad C, et al. Pancancer genome and transcriptome analyses of 1,699 paediatric leukaemias and solid tumours. Nature. 2018;555:371-6.

41. Mantere T, Kersten S, Hoischen A. Long-read sequencing emerging in medical genetics. Front Genet. 2019;10:426.

42. Euskirchen P, Bielle F, Labreche K, Kloosterman WP, Rosenberg S, Daniau M, et al. Same-day genomic and epigenomic diagnosis of brain tumors using real-time nanopore sequencing. Acta Neuropathol. 2017;134:691-703.

43. Cavelier L, Ameur A, Haggqvist S, Hoijer I, Cahill N, Olsson-Stromberg U, et al. Clonal distribution of BCR-ABL1 mutations and splice isoforms by single-molecule long-read RNA sequencing. BMC Cancer. 2015;15:45.

44. Nattestad M, Goodwin S, Ng K, Baslan T, Sedlazeck FJ, Rescheneder P, et al Complex rearrangements and oncogene amplifications revealed by longread DNA and RNA sequencing of a breast cancer cell line. Genome Res. 2018;28:1126-35.

45. Tevz G, McGrath S, Demeter R, Magrini V, Jeet V, Rockstroh A, et al. Identification of a novel fusion transcript between human relaxin-1 (RLN1) and human relaxin-2 (RLN2) in prostate cancer. Mol Cell Endocrinol. 2016; 420:159-68.

46. Kohli M, Ho Y, Hillman DW, Van Etten JL, Henzler C, Yang R, et al. Androgen receptor variant AR-V9 is coexpressed with AR-V7 in prostate cancer metastases and predicts abiraterone resistance. Clin Cancer Res. 2017;23:4704-15.

47. Gerlinger M, Rowan AJ, Horswell S, Math M, Larkin J, Endesfelder D, et al. Intratumor heterogeneity and branched evolution revealed by multiregion sequencing. N Engl J Med. 2012;366:883-92.

48. Bedard PL, Hansen AR, Ratain MJ, Siu LL. Tumour heterogeneity in the clinic. Nature. 2013;501:355-64.

49. Lee CK, Kim S, Lee JS, Lee JE, Kim SM, Yang IS, et al. Next-generation sequencing reveals novel resistance mechanisms and molecular heterogeneity in EGFR-mutant non-small cell lung cancer with acquired resistance to EGFR-TKIs. Lung Cancer. 2017;113:106-14.

50. Heitzer E, Haque IS, Roberts CES, Speicher MR. Current and future perspectives of liquid biopsies in genomics-driven oncology. Nat Rev Genet. 2019;20:71-88

51. Rossi G, Ignatiadis M. Promises and pitfalls of using liquid biopsy for precision medicine. Cancer Res. 2019:79:2798-804.

52. Scott SN, Ostrovnaya I, Lin CM, Bouvier N, Bochner BH, lyer G, et al. Next-generation sequencing of urine specimens: a novel platform for genomic analysis in patients with non-muscle-invasive urothelial carcinoma treated with bacille Calmette-Guerin. Cancer Cytopathol. 2017;125:416-26.

53. Hickmann AK, Frick M, Hadaschik D, Battke F, Bittl M, Ganslandt O, et al. Molecular tumor analysis and liquid biopsy: a feasibility investigation analyzing circulating tumor DNA in patients with central nervous system lymphomas. BMC Cancer. 2019;19:192.

54. De Mattos-Arruda L, Mayor R, Ng CKY, Weigelt B, Martinez-Ricarte F, Torrejon D, et al. Cerebrospinal fluid-derived circulating tumour DNA better represents the genomic alterations of brain tumours than plasma. Nat Commun. 2015:6:8839.

55. Dietz S, Schirmer U, Merce C, von Bubnoff N, Dahl E, Meister M, et al. Low input whole-exome sequencing to determine the representation of the tumor exome in circulating DNA of non-small cell lung cancer patients. PLoS One. 2016;11:e0161012.

56. Manier S, Park J, Capelletti M, Bustoros M, Freeman SS, Ha G, et al. Wholeexome sequencing of cell-free DNA and circulating tumor cells in multiple myeloma. Nat Commun. 2018;9:1691.

57. Deng G, Krishnakumar S, Powell AA, Zhang H, Mindrinos MN, Telli ML, et al. Single cell mutational analysis of PIK3CA in circulating tumor cells and metastases in breast cancer reveals heterogeneity, discordance, and mutation persistence in cultured disseminated tumor cells from bone marrow. BMC Cancer. 2014;14:456.

58. Baccelli I, Schneeweiss A, Riethdorf S, Stenzinger A, Schillert A, Vogel V, et al. Identification of a population of blood circulating tumor cells from breast cancer patients that initiates metastasis in a xenograft assay. Nat Biotechnol. 2013;31:539-44.

59. Lallo A, Schenk MW, Frese KK, Blackhall F, Dive C. Circulating tumor cells and CDX models as a tool for preclinical drug development. Transl Lung Cancer Res. 2017;6:397-408.

60. Bidard FC, Michiels S, Riethdorf S, Mueller V, Esserman LJ, Lucci A, et al. Circulating tumor cells in breast cancer patients treated by neoadjuvant chemotherapy: a meta-analysis. J Natl Cancer Inst. 2018;110:560-7.
61. Bidard FC, Peeters DJ, Fehm T, Nole F, Gisbert-Criado R, Mavroudis D, et al. Clinical validity of circulating tumour cells in patients with metastatic breast cancer: a pooled analysis of individual patient data. Lancet Oncol. 2014;15:406-14.

62. de Bono JS, Scher HI, Montgomery RB, Parker C, Miller MC, Tissing H, et al. Circulating tumor cells predict survival benefit from treatment in metastatic castration-resistant prostate cancer. Clin Cancer Res. 2008;14:6302-9.

63. Antonarakis ES, Lu C, Luber B, Wang H, Chen Y, Zhu Y, et al. Clinical significance of androgen receptor splice variant-7 mRNA detection in circulating tumor cells of men with metastatic castration-resistant prostate cancer treated with first- and second-line abiraterone and enzalutamide. J Clin Oncol. 2017;35:2149-56.

64. Sacher AG, Paweletz C, Dahlberg SE, Alden RS, O'Connell A, Feeney N, et al. Prospective validation of rapid plasma genotyping for the detection of EGFR and KRAS mutations in advanced lung cancer. JAMA Oncol. 2016;2: 1014-22.

65. Abbosh C, Birkbak NJ, Wilson GA, Jamal-Hanjani M, Constantin T, Salari R, et al. Phylogenetic ctDNA analysis depicts early-stage lung cancer evolution. Nature. 2017:545:446-51.

66. Scherer F, Kurtz DM, Newman AM, Stehr H, Craig AF, Esfahani MS, et al. Distinct biological subtypes and patterns of genome evolution in lymphoma revealed by circulating tumor DNA. Sci Transl Med. 2016;8: $364 r a 155$.

67. Gibney GT, Weiner LM, Atkins MB. Predictive biomarkers for checkpoint inhibitor-based immunotherapy. Lancet Oncol. 2016;17:e542-51.

68. Mazel M, Jacot W, Pantel K, Bartkowiak K, Topart D, Cayrefourcq L, et al. Frequent expression of PD-L1 on circulating breast cancer cells. Mol Oncol. 2015:9:1773-82.

69. Schott DS, Pizon M, Pachmann U, Pachmann K. Sensitive detection of PD-L1 expression on circulating epithelial tumor cells (CETCS) could be a potential biomarker to select patients for treatment with PD-1/PD-L1 inhibitors in early and metastatic solid tumors. Oncotarget. 2017:8:72755-72.

70. Warren JD, Xiong W, Bunker AM, Vaughn CP, Furtado LV, Roberts WL, et al. Septin 9 methylated DNA is a sensitive and specific blood test for colorectal cancer. BMC Med. 2011;9:133.

71. Rzepiel A, Kutszegi N, Gezsi A, Sagi JC, Egyed B, Peter G, et al. Circulating microRNAs as minimal residual disease biomarkers in childhood acute lymphoblastic leukemia. J Transl Med. 2019;17:372.

72. Sozzi G, Boeri M, Rossi M, Verri C, Suatoni P, Bravi F, et al. Clinical utility of a plasma-based miRNA signature classifier within computed tomography lung cancer screening: a correlative MILD trial study. J Clin Oncol. 2014;32:768-73.

73. Lasham A, Fitzgerald SJ, Knowlton N, Robb T, Tsai P, Black MA, et al. A predictor of early disease recurrence in patients with breast cancer using a cell-free RNA and protein liquid biopsy. Clin Breast Cancer. 2019. https://doi. org/10.1016/j.clbc.2019.07.003.

74. Witwer KW. Circulating microRNA biomarker studies: pitfalls and potential solutions. Clin Chem. 2015;61:56-63.

75. Geeurickx E, Hendrix A. Targets, pitfalls and reference materials for liquid biopsy tests in cancer diagnostics. Mol Asp Med. 2019. https://doi.org/10. 1016/j.mam.2019.10.005.

76. Prawira A, Pugh TJ, Stockley TL, Siu LL. Data resources for the identification and interpretation of actionable mutations by clinicians. Ann Oncol. 2017; 28:946-57.

77. Chakravarty D, Gao J, Phillips SM, Kundra R, Zhang H, Wang J, et al. OncoKB: a precision oncology knowledge base. JCO Precis Oncol. 2017;2017. https:// doi.org/10.1200/PO.17.00011.

78. Griffith M, Spies NC, Krysiak K, McMichael JF, Coffman AC, Danos AM, et al. CIViC is a community knowledgebase for expert crowdsourcing the clinical interpretation of variants in cancer. Nat Genet. 2017:49:170-4.

79. Yue Z, Zhao L, Xia J. dbCPM: a manually curated database for exploring the cancer passenger mutations. Brief Bioinform. 2018. doi: https://doi.org/10. 1093/bib/bby105.

80. Liu X, Wu C, Li C, Boerwinkle E. dbNSFP v3.0: a one-stop database of functional predictions and annotations for human nonsynonymous and splice-site SNVs. Hum Mutat. 2016;37:235-41.

81. Butkiewicz M, Bush WS. In silico functional annotation of genomic variation. Curr Protoc Hum Genet. 2016;88:6.15.1-6.15.17.

82. Amberger JS, Hamosh A. Searching Online Mendelian Inheritance in Man (OMIM): a knowledgebase of human genes and genetic phenotypes. Curr Protoc Bioinformatics. 2017;58:1.2.1-1.2.12. 
83. Landrum MJ, Lee JM, Benson M, Brown G, Chao C, Chitipiralla S, et al. ClinVar: public archive of interpretations of clinically relevant variants. Nucleic Acids Res. 2016:44:D862-8.

84. Yu Y, Wang Y, Xia Z, Zhang X, Jin K, Yang J, et al. PreMedKB: an integrated precision medicine knowledgebase for interpreting relationships between diseases, genes, variants and drugs. Nucleic Acids Res. 2019;47:D1090-101.

85. Madhavan S, Ritter D, Micheel C, Rao S, Roy A, Sonkin D, et al. ClinGen Cancer Somatic Working Group_standardizing and democratizing access to cancer molecular diagnostic data to drive translational research. Pac Symp Biocomput. 2018;23:247-58.

86. Li MM, Datto M, Duncavage EJ, Kulkarni S, Lindeman NI, Roy S, et al. Standards and guidelines for the interpretation and reporting of sequence variants in cancer: a joint consensus recommendation of the Association for Molecular Pathology, American Society of Clinical Oncology, and College of American Pathologists. J Mol Diagn. 2017;19:4-23.

87. Mandelker D, Donoghue MTA, Talukdar S, Bandlamudi C, Srinivasan P, Vivek $M$, et al. Germline-focused analysis of tumour-only sequencing: recommendations from the ESMO Precision Medicine Working Group. Ann Oncol. 2019. https://doi.org/10.1093/annonc/mdz136.

88. Hampel $H$, Pearlman R, Beightol M, Zhao W, Jones D, Frankel WL, et al. Assessment of tumor sequencing as a replacement for Lynch syndrome screening and current molecular tests for patients with colorectal cancer. JAMA Oncol. 2018;4:806-13.

89. van der Velden DL, van Herpen CML, van Laarhoven HWM, Smit EF, Groen HJM, Willems SM, et al. Molecular tumor boards: current practice and future needs. Ann Oncol. 2017:28:3070-5.

90. Rolfo C, Manca P, Salgado R, Van Dam P, Dendooven A, Machado Coelho A, et al. Multidisciplinary molecular tumour board: a tool to improve clinical practice and selection accrual for clinical trials in patients with cancer. ESMO Open. 2018:3:e000398.

91. Harada S, Arend R, Dai Q, Levesque JA, Winokur TS, Guo R, et al. Implementation and utilization of the molecular tumor board to guide precision medicine. Oncotarget. 2017:8:57845-54.

92. Newman EA, Guest AB, Helvie MA, Roubidoux MA, Chang AE, Kleer CG, et al. Changes in surgical management resulting from case review at a breast cancer multidisciplinary tumor board. Cancer. 2006;107:2346-51.

93. Charara RN, Kreidieh FY, Farhat RA, Al-Feghali KA, Khoury KE, Haydar A, et al. Practice and impact of multidisciplinary tumor boards on patient management: a prospective study. J Glob Oncol. 2017;3:242-9.

94. Gray SW, Hicks-Courant K, Cronin A, Rollins BJ, Weeks JC. Physicians' attitudes about multiplex tumor genomic testing. J Clin Oncol. 2014;32:1317-23.

95. Freedman AN, Klabunde CN, Wiant K, Enewold L, Gray SW, Filipski KK, et al, Use of next-generation sequencing tests to guide cancer treatment: results from a nationally representative survey of oncologists in the United States. JCO Precis Oncol. 2018. https://doi.org/10.1200/PO.18.00169.

96. Hyman DM, Solit DB, Arcila ME, Cheng DT, Sabbatini P, Baselga J, et al. Precision medicine at Memorial Sloan Kettering Cancer Center: clinical nextgeneration sequencing enabling next-generation targeted therapy trials. Drug Discov Today. 2015;20:1422-8.

97. Le Tourneau C, Delord JP, Goncalves A, Gavoille C, Dubot C, Isambert N, et al. Molecularly targeted therapy based on tumour molecular profiling versus conventional therapy for advanced cancer (SHIVA): a multicentre, open-label, proof-of-concept, randomised, controlled phase 2 trial. Lancet Oncol. 2015;16:1324-34.

98. Belin L, Kamal M, Mauborgne C, Plancher C, Mulot F, Delord JP, et al. Randomized phase II trial comparing molecularly targeted therapy based on tumor molecular profiling versus conventional therapy in patients with refractory cancer: cross-over analysis from the SHIVA trial. Ann Oncol. 2017;28:590-6.

99. Turski ML, Vidwans SJ, Janku F, Garrido-Laguna I, Munoz J, Schwab R, et al. Genomically driven tumors and actionability across histologies: BRAFmutant cancers as a paradigm. Mol Cancer Ther. 2016;15:533-47.

100. Vogelstein B, Papadopoulos N, Velculescu VE, Zhou S, Diaz LA Jr, Kinzler KW. Cancer genome landscapes. Science. 2013;339:1546-58,

101. Le DT, Uram JN, Wang H, Bartlett BR, Kemberling H, Eyring AD, et al. PD-1 blockade in tumors with mismatch-repair deficiency. N Engl J Med. 2015; 372:2509-20.

102. Nussinov R, Jang $H, T$ sai $C J$, Cheng F. Precision medicine and driver mutations: computational methods, functional assays and conformational principles for interpreting cancer drivers. PLoS Comput Biol. 2019;15:e1006658.

103. Mullard A. FDA approves landmark tissue-agnostic cancer drug. Nat Rev Drug Discov. 2018;18:7.
104. Hsiao SJ, Zehir A, Sireci AN, Aisner DL. Detection of tumor NTRK gene fusions to identify patients who may benefit from tyrosine kinase (TRK) inhibitor therapy. J Mol Diagn. 2019;21:553-71.

105. Jacquinot Q, Meneveau N, Chatot M, Bonnetain F, Degano B, Bouhaddi M et al. A phase 2 randomized trial to evaluate the impact of a supervised exercise program on cardiotoxicity at 3 months in patients with HER2 overexpressing breast cancer undergoing adjuvant treatment by trastuzumab: design of the CARDAPAC study. BMC Cancer. 2017;17:425.

106. Chapuy B, Stewart C, Dunford AJ, Kim J, Kamburov A, Redd RA, et al. Molecular subtypes of diffuse large B cell lymphoma are associated with distinct pathogenic mechanisms and outcomes. Nat Med. 2018;24:679-90.

107. Davies H, Glodzik D, Morganella S, Yates LR, Staaf J, Zou X, et al. HRDetect is a predictor of BRCA1 and BRCA2 deficiency based on mutational signatures. Nat Med. 2017;23:517-25.

108. Schulze K, Imbeaud S, Letouze E, Alexandrov LB, Calderaro J, Rebouissou S, et al. Exome sequencing of hepatocellular carcinomas identifies new mutational signatures and potential therapeutic targets. Nat Genet. 2015;47:505-11.

109. Tutt A, Tovey H, Cheang MCU, Kernaghan S, Kilburn L, Gazinska P, et al. Carboplatin in BRCA1/2-mutated and triple-negative breast cancer BRCAness subgroups: the TNT trial. Nat Med. 2018;24:628-37.

110. Guinney J, Dienstmann R, Wang X, de Reynies A, Schlicker A, Soneson C, et al. The consensus molecular subtypes of colorectal cancer. Nat Med. 2015;21:1350-6

111. Lord CJ, Ashworth A. BRCAness revisited. Nat Rev Cancer. 2016;16:110-20.

112. Robinson D, Van Allen EM, Wu YM, Schultz N, Lonigro RJ, Mosquera JM, et al. Integrative clinical genomics of advanced prostate cancer. Cell. 2015; 161:1215-28.

113. Nielsen T, Wallden B, Schaper C, Ferree S, Liu S, Gao D, et al. Analytical validation of the PAM50-based Prosigna breast cancer prognostic gene signature assay and nCounter analysis system using formalin-fixed paraffinembedded breast tumor specimens. BMC Cancer. 2014;14:177.

114. Scott DW, Wright GW, Williams PM, Lih CJ, Walsh W, Jaffe ES, et al. Determining cell-of-origin subtypes of diffuse large B-cell lymphoma using gene expression in formalin-fixed paraffin-embedded tissue. Blood. 2014; 123:1214-7.

115. Andre F, Ismaila N, Henry NL, Somerfield MR, Bast RC, Barlow W, et al. Use of biomarkers to guide decisions on adjuvant systemic therapy for women with early-stage invasive breast cancer: ASCO clinical practice guideline update-integration of results from TAlLORx. J Clin Oncol. 2019;37:1956-64.

116. Senft D, Leiserson MDM, Ruppin E, Ronai ZA. Precision oncology: the road ahead. Trends Mol Med. 2017;23:874-98.

117. Rodon J, Soria JC, Berger R, Batist G, Tsimberidou A, Bresson C, et al. Challenges in initiating and conducting personalized cancer therapy trials: perspectives from WINTHER, a Worldwide Innovative Network (WIN) consortium trial. Ann Oncol. 2015;26:1791-8.

118. Horak P, Klink B, Heining C, Groschel S, Hutter B, Frohlich M, et al. Precision oncology based on omics data: the NCT Heidelberg experience. Int J Cancer. 2017;141:877-86.

119. Nebbioso A, Tambaro FP, Dell'Aversana C, Altucci L. Cancer epigenetics: moving forward. PLoS Genet. 2018;14:e1007362.

120. Stunnenberg HG, International Human Epigenome Consortium, Hirst M. The International Human Epigenome Consortium: a blueprint for scientific collaboration and discovery. Cell. 2016;167:1145-9.

121. Bernstein BE, Stamatoyannopoulos JA, Costello JF, Ren B, Milosavljevic A, Meissner A, et al. The NIH Roadmap Epigenomics Mapping Consortium. Nat Biotechnol. 2010;28:1045-8.

122. Teixeira VH, Pipinikas CP, Pennycuick A, Lee-Six H, Chandrasekharan D, Beane J, et al. Deciphering the genomic, epigenomic, and transcriptomic landscapes of pre-invasive lung cancer lesions. Nat Med. 2019;25:517-25

123. Yoshimi A, Lin KT, Wiseman DH, Rahman MA, Pastore A, Wang B, et al. Coordinated alterations in RNA splicing and epigenetic regulation drive leukaemogenesis. Nature. 2019:574:273-7.

124. Klughammer J, Kiesel B, Roetzer T, Fortelny N, Nemc A, Nenning KH, et al. The DNA methylation landscape of glioblastoma disease progression shows extensive heterogeneity in time and space. Nat Med. 2018;24:1611-24

125. Hinoue $T$, Weisenberger DJ, Lange CP, Shen $H$, Byun HM, Van Den Berg D, et al. Genome-scale analysis of aberrant DNA methylation in colorectal cancer. Genome Res. 2012;22:271-82. 
126. Conway JR, Kofman E, Mo SS, Elmarakeby H, Van Allen E. Genomics of response to immune checkpoint therapies for cancer: implications for precision medicine. Genome Med. 2018;10:93.

127. Cristescu R, Mogg R, Ayers M, Albright A, Murphy E, Yearley J, et al. Pantumor genomic biomarkers for PD-1 checkpoint blockade-based immunotherapy. Science. 2018;362:eaar3593.

128. Rizvi NA, Hellmann MD, Snyder A, Kvistborg P, Makarov V, Havel JJ, et al. Cancer immunology. Mutational landscape determines sensitivity to PD-1 blockade in non-small cell lung cancer. Science. 2015;348:124-8.

129. Snyder A, Makarov V, Merghoub T, Yuan J, Zaretsky JM, Desrichard A, et al. Genetic basis for clinical response to CTLA-4 blockade in melanoma. N Engl J Med. 2014;371:2189-99.

130. Gandara DR, Paul SM, Kowanetz M, Schleifman E, Zou W, Li Y, et al. Bloodbased tumor mutational burden as a predictor of clinical benefit in non-smallcell lung cancer patients treated with atezolizumab. Nat Med. 2018;24:1441-8.

131. Das M. Blood-based tumour mutational burden analysis in NSCLC. Lancet Oncol. 2018:19:e446.

132. Allgauer M, Budczies J, Christopoulos P, Endris V, Lier A, Rempel E, et al. Implementing tumor mutational burden (TMB) analysis in routine diagnostics - a primer for molecular pathologists and clinicians. Transl Lung Cancer Res. 2018;7:703-15.

133. Stenzinger A, Allen JD, Maas J, Stewart MD, Merino DM, Wempe MM, et al. Tumor mutational burden standardization initiatives: recommendations for consistent tumor mutational burden assessment in clinical samples to guide immunotherapy treatment decisions. Genes Chromosomes Cancer. 2019;58:578-88.

134. Yarchoan M, Hopkins A, Jaffee EM. Tumor mutational burden and response rate to PD-1 inhibition. N Engl J Med. 2017;377:2500-1.

135. Nghiem PT, Bhatia S, Lipson EJ, Kudchadkar RR, Miller NJ, Annamalai L, et al. PD-1 blockade with pembrolizumab in advanced Merkel-cell carcinoma. N Engl J Med. 2016;374:2542-52.

136. Shin DS, Zaretsky JM, Escuin-Ordinas H, Garcia-Diaz A, Hu-Lieskovan S, Kalbasi A, et al. Primary resistance to PD-1 blockade mediated by JAK1/2 mutations. Cancer Discov. 2017;7:188-201.

137. George S, Miao D, Demetri GD, Adeegbe D, Rodig SJ, Shukla S, et al. Loss of PTEN is associated with resistance to anti-PD-1 checkpoint blockade therapy in metastatic uterine leiomyosarcoma. Immunity. 2017;46:197-204.

138. Gettinger S, Choi J, Hastings K, Truini A, Datar I, Sowell R, et al. Impaired HLA class I antigen processing and presentation as a mechanism of acquired resistance to immune checkpoint inhibitors in lung cancer. Cancer Discov. 2017;7:1420-35

139. Brabetz S, Leary SES, Grobner SN, Nakamoto MW, Seker-Cin H, Girard EJ, et al. A biobank of patient-derived pediatric brain tumor models. Nat Med. 2018;24:1752-61.

140. Tredan O, Corset V, Wang Q, Varnier R, Pacaud C, Torroja A, et al. Routine molecular screening of advanced refractory cancer patients: an analysis of the first 2490 patients of the ProfiLER study. J Clin Oncol. 2017:35. https:// doi.org/10.1200/JCO.2017.35.18_suppl.LBA100.

141. Tredan O, Wang Q, Pissaloux D, Cassier P, de la Fouchardiere A, Fayette J, et al. Molecular screening program to select molecular-based recommended therapies for metastatic cancer patients: analysis from the ProfiLER trial. Ann Oncol. 2019;30:757-65.

142. Cobain EF, Robinson DR, Wu Y-M, Everett J, Rabban E, Kumar C, et al. Clinical application of comprehensive next generation sequencing in the management of metastatic cancer in adults. J Clin Oncol. 2017;35. https:// doi.org/10.1200/JCO.2017.35.15_suppl.101.

143. Tannock IF, Hickman JA. Molecular screening to select therapy for advanced cancer? Ann Oncol. 2019;30:661-3.

144. Jonsson P, Bandlamudi C, Cheng ML, Srinivasan P, Chavan SS, Friedman ND, et al. Tumour lineage shapes BRCA-mediated phenotypes. Nature. 2019;571:576-9.

145. Vassy JL, Bates DW, Murray MF. Appropriateness: a key to enabling the use of genomics in clinical practice? Am J Med. 2016;129:551-3.

146. Christensen KD, Vassy JL, Jamal L, Lehmann LS, Slashinski MJ, Perry DL, et al. Are physicians prepared for whole genome sequencing? A qualitative analysis. Clin Genet. 2016;89:228-34

147. Dorschner MO, Amendola LM, Shirts BH, Kiedrowski L, Salama J, Gordon AS, et al. Refining the structure and content of clinical genomic reports. Am J Med Genet C Semin Med Genet. 2014;166C:85-92.

148. McLaughlin HM, Ceyhan-Birsoy O, Christensen KD, Kohane IS, Krier J, Lane WJ, et al. A systematic approach to the reporting of medically relevant findings from whole genome sequencing. BMC Med Genet. 2014;15:134.
149. CIViC: clinical interpretations of variants in cancer. https://civicdb.org/home. Accessed 27 Nov 2019.

150. OncoKB: precision oncology knowledge base. https://oncokb.org/. Accessed 27 Nov 2019.

151. Myers RE, Wolf T, Shwae P, Hegarty S, Peiper SC, Waldman SA. A survey of physician receptivity to molecular diagnostic testing and readiness to act on results for early-stage colon cancer patients. BMC Cancer. 2016;16:766.

152. Johnson A, Zeng J, Bailey AM, Holla V, Litzenburger B, Lara-Guerra H, et al. The right drugs at the right time for the right patient: the MD Anderson precision oncology decision support platform. Drug Discov Today. 2015;20:1433-8.

153. Kurnit KC, Dumbrava EEl, Litzenburger B, Khotskaya YB, Johnson AM, Yap TA, et al. Precision oncology decision support: current approaches and strategies for the future. Clin Cancer Res. 2018;24:2719-31.

154. Giuse NB, Kusnoor SV, Koonce TY, Naylor HM, Chen SC, Blasingame MN, et al. Guiding oncology patients through the maze of precision medicine. J Health Commun. 2016;21(Suppl 1):5-17.

155. Stjepanovic N, Stockley TL, Bedard PL, McCuaig JM, Aronson M, Holter S, et al. Additional germline findings from a tumor profiling program. BMC Med Genet. 2018;11:65.

156. Huang KL, Mashl RJ, Wu Y, Ritter Dl, Wang J, Oh C, et al. Pathogenic germline variants in 10,389 adult cancers. Cell. 2018;173:355-70.

157. Bertelsen B, Tuxen IV, Yde CW, Gabrielaite M, Torp MH, Kinalis S, et al. High frequency of pathogenic germline variants within homologous recombination repair in patients with advanced cancer. NPJ Genom Med. 2019;4:13.

158. Schrader KA, Cheng DT, Joseph V, Prasad M, Walsh M, Zehir A, et al. Germline variants in targeted tumor sequencing using matched normal DNA. JAMA Oncol. 2016;2:104-11.

159. Ersek JL, Black LJ, Thompson MA, Kim ES. Implementing precision medicine programs and clinical trials in the community-based oncology practice: barriers and best practices. Am Soc Clin Oncol Educ Book. 2018;38:188-96.

160. ECOG-ACRIN Cancer Research Group. Pre-test genetic education and remote genetic counseling in communicating tumor profiling results to patients with advanced cancer. NCT02823652. https://clinicaltrials.gov/ct2/ show/NCT02823652. Accessed 27 Nov 2019.

161. Harrington JA, Hernandez-Guerrero TC, Basu B. Early phase clinical trial designs - state of play and adapting for the future. Clin Oncol (R Coll Radiol). 2017;29:770-7.

162. Canadian Cancer Trials Group. Canadian Profiling and Targeted Agent Utilization Trial (CAPTUR). NCT03297606. https://ClinicalTrials.gov/show/ NCT03297606. Accessed 27 Nov 2019.

163. Garralda E, Dienstmann R, Piris-Gimenez A, Brana I, Rodon J, Tabernero J. New clinical trial designs in the era of precision medicine. Mol Oncol. 2019; 13:549-57.

164. Renfro LA, Sargent DJ. Statistical controversies in clinical research: basket trials, umbrella trials, and other master protocols: a review and examples. Ann Oncol. 2017;28:34-43.

165. National Cancer Institute (NCI). Targeted therapy directed by genetic testing in treating patients with advanced refractory solid tumors, lymphomas, or multiple myeloma (The MATCH Screening Trial). NCT02465060. https:// ClinicalTrials.gov/show/NCT02465060. Accessed 27 Nov 2019.

166. American Society of Clinical Oncology. TAPUR: testing the use of Food and Drug Administration (FDA) approved drugs that target a specific abnormality in a tumor gene in people with advanced stage cancer. NCT02693535. https://ClinicalTrials.gov/show/NCT02693535. Accessed 27 Nov 2019.

167. The Netherlands Cancer Institute. The Drug Rediscovery Protocol (DRUP trial). NCT02925234. https://ClinicalTrials.gov/show/NCT02925234. Accessed 27 Nov 2019.

168. Jhaveri KL, Makker V, Wang XV, Chen AP, Flaherty K, Conley BA, et al. Adotrastuzumab emtansine (T-DM1) in patients (pts) with HER2 amplified (amp) tumors excluding breast and gastric/gastro-esophageal junction (GEJ) adenocarcinomas: results from the National Cancer Institute (NCI) Molecular Analysis for Therapy Choice (MATCH) trial. J Clin Oncol. 2018;36. https://doi. org/10.1200/JCO.2018.36.15_suppl.100.

169. Chae YK, Vaklavas C, Cheng HH, Hong F, Harris L, Mitchell EP, et al. Molecular analysis for therapy choice (MATCH) arm W: phase II study of AZD4547 in patients with tumors with aberrations in the FGFR pathway. J Clin Oncol. 2018;36. https://doi.org/10.1200/JCO.2018.36.15 suppl.2503. 
170. Krop IE, Jegede O, Grilley-Olson JE, Lauring JD, Hamilton SR, Zwiebel JA, et al. Results from molecular analysis for therapy choice (MATCH) arm I: taselisib for PIK3CA-mutated tumors. J Clin Oncol. 2018;36. https://doi.org/ 10.1200/JCO.2018.36.15_suppl.101.

171. National Cancer Institute (NCI). Genetic testing in screening patients with Stage IB-IIIA non-small cell lung cancer that has been or will be removed by surgery (The ALCHEMIST Screening Trial). NCT02194738. https:// clinicaltrials.gov/ct2/show/NCT02194738. Accessed 27 Nov 2019.

172. van der Velden $\mathrm{DL}$, Hoes $L R$, van der Wijngaart $H$, van Berge Henegouwen JM, van Werkhoven E, Roepman P, et al. The Drug Rediscovery protocol facilitates the expanded use of existing anticancer drugs. Nature. 2019;574:127-31.

173. Eckhardt SG, Lieu C. Is precision medicine an oxymoron? JAMA Oncol. 2019;5:142-3.

174. Sicklick JK, Kato S, Okamura R, Schwaederle M, Hahn ME, Williams CB, et al. Molecular profiling of cancer patients enables personalized combination therapy: the I-PREDICT study. Nat Med. 2019;25:744-50.

175. Zeng J, Shufean MA, Khotskaya Y, Yang D, Kahle M, Johnson A, et al. OCTANE: Oncology Clinical Trial Annotation Engine. JCO Clin Cancer Inform. 2019;3:1-11.

176. University Health Network-Drug Development Program (UHN-DDP). Phase 1 Clinical Trials: part of the Princess Margaret Cancer Center. https://www. uhnddp.ca/. Accessed 26 Nov 2019.

177. Bussey KJ, Kane D, Sunshine M, Narasimhan S, Nishizuka S, Reinhold WC, et al. MatchMiner: a tool for batch navigation among gene and gene product identifiers. Genome Biol. 2003:4:R27.

178. Haddad TC, Helgeson J, Pomerleau K, Makey M, Lombardo P, Coverdill S, et al. Impact of a cognitive computing clinical trial matching system in an ambulatory oncology practice. J Clin Oncol. 2018;36. https://doi.org/10. 1200/JCO.2018.36.15_suppl.6550.

179. Mittra A, Moscow JA. Future approaches to precision oncology-based clinical trials. Cancer J. 2019;25:300-4.

\section{Publisher's Note}

Springer Nature remains neutral with regard to jurisdictional claims in published maps and institutional affiliations. 